\title{
Inhibition of astroglial connexin43 hemichannels with TAT-Gap19 exerts anticonvulsant effects in rodents
}

\author{
Laura Walrave $^{1}$ (1) | Anouk Pierre ${ }^{1}$ | Giulia Albertini ${ }^{1}$ | Najat Aourz ${ }^{1}$ | \\ Dimitri De Bundel $^{1}$ | Ann Van Eeckhaut ${ }^{1}$ ( 1 | Mathieu Vinken ${ }^{2}$ | \\ Christian Giaume $^{3}$ | Luc Leybaert ${ }^{4 *}$ | Ilse Smolders ${ }^{1 *}$
}

\begin{abstract}
${ }^{1}$ Department of Pharmaceutical Chemistry, Drug Analysis and Drug Information, Research group Experimental Pharmacology (EFAR), Center for Neurosciences (C4N), Vrije Universiteit Brussel, Laarbeeklaan 103, Brussels, 1090, Belgium

${ }^{2}$ Department of In Vitro Toxicology and Dermato-Cosmetology, Vrije Universiteit Brussel, Laarbeeklaan 103, Brussels, 1090, Belgium

${ }^{3}$ Center for Interdisciplinary Research in Biology (CIRB), Collège de France, Paris, 75005, France

${ }^{4}$ Physiology group, Department of Basic Medical Sciences, Ghent University, De Pintelaan 185, Ghent, 9000, Belgium
\end{abstract}

\section{Correspondence}

Ilse Smolders, Department of

Pharmaceutical Chemistry, Drug Analysis

and Drug Information, EFAR, C4N, Vrije

Universiteit Brussel, Laarbeeklaan 103,

Brussels, 1090, Belgium.

Email: Ilse.Smolders@vub.be

\section{Funding information}

Vrije Universiteit Brussel (VUB), Grant/ Award Number: OZR2102; European Research Council (ERC), Grant/Award Number: 335476; Fund for scientific Research Flanders (FWO Vlaanderen), Grant/Award Numbers: G.0298.11, G.0571.12, G.0A54.13 and G.0320.15; FWO Vlaanderen, Grant/Award Number: G.0A82.13N; Interuniversity Attraction Poles Program, Grant/Award Number: P7/ 10; Ghent University (Special Research Fund (BOF); Geneeskundige Stichting Koningin Elisabeth, Grant/Award Number: STI.DI2.2017.0004.01

\begin{abstract}
Accumulating evidence shows a key function for astrocytic connexin43 (Cx43) signaling in epilepsy. However, the lack of experimental distinction between $\mathrm{C} \times 43$ gap junction channels (GJCs) and hemichannels ( $\mathrm{HCs}$ ) has impeded the identification of the exact contribution of either channe configurations to epilepsy. We therefore investigated whether TAT-Gap19, a Cx mimetic peptide that inhibits $\mathrm{C} \times 43 \mathrm{HCs}$ but not the corresponding $\mathrm{C} \times 43 \mathrm{GJCs}$, influences experimentally induced seizures in rodents. Dye uptake experiments in acute hippocampal slices of mice demonstrated that astroglial $\mathrm{Cx} 43 \mathrm{HCs}$ open in response to the chemoconvulsant pilocarpine and this was inhibited by TAT-Gap19. In vivo, pilocarpine-induced seizures as well as the accompanying increase in D-serine microdialysate levels were suppressed by Cx43 HC inhibition. Moreover, the anticonvulsant action of TAT-Gap19 was reversed by exogenous D-serine administration, suggesting that $\mathrm{C} \times 43 \mathrm{HC}$ inhibition protects against seizures by lowering extracellular D-serine levels. The anticonvulsive properties of $\mathrm{C} \times 43 \mathrm{HC}$ inhibition were further confirmed in electrical seizure mouse models, i.e. an acute $6 \mathrm{Hertz}(\mathrm{Hz})$ model of refractory seizures and a chronic $6 \mathrm{~Hz}$ corneal kindling model. Collectively, these results indicate that $\mathrm{C} \times 43 \mathrm{HCs}$ play a role in seizures and underscore their potential as a novel and druggable target in epilepsy treatment.
\end{abstract}

\section{KEYWORDS}

astrocytes, connexin43 hemichannels, pilocarpine, seizures, TAT-Gap19

\begin{abstract}
Abbreviations: [], extracellular ion concentration; [], intracellular ion concentration; aCSF, artificial cerebrospinal fluid; AP, anterior-posterior; ASDs, anti-seizure drugs; ATP, adenosine triphosphate; CBX, carbenoxolone; $\mathrm{CL}$, cytoplasmic loop; $\mathrm{CT}$, carboxy-terminal tail; Ctr, control condition; $\mathrm{Cx}(\mathrm{s})(43)$, connexin(s)(43); DAAO, D-amino acid oxidase; DV, dorso-ventral; eGFP, enhanced green fluorescent protein; ECoG, electrocorticograph(y/ic); EtBr, ethidium bromide; ETSP, Epilepsy Therapy Screening Program; GFAP, glial fibrillary acidic protein; GABA, gamma-aminobutyric acid; GJC(s), gap junction channel(s); GJCC, gap junction channel coupling; HC(s), hemichannel(s); HPLC, high-performance liquid chromatography; Hz, Hertz; i.c.v., intracerebroventricular(ly); i.p., intraperitoneal(Iy); ML, mediallateral; NIH, National Institutes of Health; NINDS, National Institute of Neurological Disorders and Stroke; NMDA, N-methyl-D-aspartate; PBS, phosphate buffered saline; RT, room temperature; s.c., subcutaneous(ly); scrTG19, scrambled TAT-Gap19; SEM, standard error of the mean; SSS, seizure severity score; TAT, transactivator of transcription; TG19, TAT-Gap19; TSSS, total seizure severity score; P40, 40 min pilocarpine incubation; WMS, Wilcoxon matched-pairs signedrank.
\end{abstract}

*Shared senior author 


\section{1 | INTRODUCTION}

Despite the large number of marketed anti-seizure drugs (ASDs), one third of patients with epilepsy suffer from intolerable side effects and/ or drug resistance (Kwan, Schachter, \& Brodie, 2011). Pharmacoresistance to several ASDs can be explained by the similar mechanisms of action, which are mainly targeting neuronal mechanisms (Janigro \& Walker, 2014). The discovery of ASDs with distinct activity profiles (e.g., targeting non-neuronal elements) has therefore become an important new avenue for the development of epilepsy treatments (Baulac \& Pitkänen, 2008). In line with this notion, the present study evaluates the potential of astroglial connexin (Cx) hemichannels ( $\mathrm{HCs}$ ) as novel druggable targets for epilepsy. Astrocytes express Cx43 and Cx30; here we focus on $\mathrm{Cx} 43$ as the major astrocytic Cx (Orellana, Retamal, Moraga-Amaro, \& Stehberg, 2016).

Cx43 proteins are building blocks of two different channel types in astrocytes (Nagy \& Rash, 2000; Naus, Bechberger, Caveney, \& Wilson, 1991; Orellana et al., 2016). While Cx43 gap junction channels (GJCs) connect two adjacent astrocytes, $\mathrm{C} \times 43 \mathrm{HCs}$ are located between the cytosol of a single astrocyte and the extracellular environment (Abudara et al., 2014). When open, Cx43 HCs form a high conductance pathway (single channel conductance of $\sim 220 \mathrm{pS}$ ) allowing the passage of molecules and ions below $\sim 1.5 \mathrm{kDa}$ (Wang et al., 2012). Some controversies regarding the functional characteristics of $\mathrm{Cx} 43 \mathrm{HCs}$ are described (reviewed in Nielsen, Hansen, Ransom, Nielsen, \& MacAulay, 2017), however, several research papers demonstrate that, if opening is limited in nature, glial Cx43 HCs may provide a pathway for controlled release of various neuroactive substances, called gliotransmitters (e.g., glutamate and adenosine triphosphate (ATP) release; Orellana et al., 2011; Ye, Wyeth, Baltan-Tekkok, \& Ransom, 2003) or the entry of major signaling ions like $\mathrm{Ca}^{2+}$. The latter will transiently increase the intracellular $\mathrm{Ca}^{2+}$ concentration $\left(\left[\mathrm{Ca}^{2+}\right]_{\mathrm{i}}\right)$, which can affect a variety of physiological cell functions (e.g., regulation of cell volume and synaptic activity; Chever, Lee, \& Rouach, 2014; Chever, Pannasch, Ezan, \& Rouach, 2014; Lohman \& Isakson, 2014; Meunier et al., 2017; Giaume, Leybaert, Naus, \& Sáez, 2013; Orellana et al., 2016; Pannasch \& Rouach, 2013; Torres et al., 2012; Walrave et al., 2016).

Sustained $\mathrm{Cx} 43 \mathrm{HC}$ opening on the other hand could release excessive amounts of chemically active molecules (e.g., damageassociated ATP release), lead to disturbed transmembrane ion fluxes and loss of essential metabolites. $\mathrm{C} \times 43 \mathrm{HC}$ opening might therefore promote deleterious results, which has been demonstrated in several pathological conditions, such as ischemia, Alzheimer's disease and inflammation (Abudara et al., 2015; De Bock et al., 2014; Giaume et al., 2013; Montero \& Orellana, 2015; Vinken, 2015; Wei et al., 2014). While in vivo glutamate release linked to $\mathrm{C} \times 43 \mathrm{HC}$ opening has already been demonstrated in a hypoxia/ischemia rat model (Li et al., 2015; use of Gap26 mimetic peptide), up to now no in vivo reports are available pinpointing the contribution of $\mathrm{C} \times 43 \mathrm{HCs}$ to D-serine release. Their potential function as pathological pores as well as their predominant and high expression by astrocytes in the hippocampus (Chever, Lee, et al., 2014; Giaume \& Theis, 2010; Kang et al., 2008; Mylvaganam et al., 2010; Ye et al., 2003), a brain region crucially involved in epilepsy, led us to hypothesize that in vivo $\mathrm{Cx} 43 \mathrm{HC}$ inhibition may be a novel treatment strategy for epilepsy.

An increasing number of studies point to a role for $\mathrm{Cx} 43$ signaling in epilepsy (for reviews see Carlen, 2012; Jin \& Chen, 2011; Mylvaganam, Ramani, Krawczyk, \& Carlen, 2014). Nevertheless, due to a lack of experimental tools, the exact contribution of either $\mathrm{Cx} 43 \mathrm{HC}$ or $\mathrm{Cx} 43$ GJC inhibition in epilepsy remains to be elucidated. Indeed, the use of Cx knock-out animals or non-selective inhibitors have led to contradictory results, resulting in either proconvulsant or anticonvulsant effects (Carlen, 2012). In knock-out mice, both HCs and GJCs are deleted, as these channels are built up by the same proteins, and compensatory mechanisms are possible (Nielsen et al., 2017; Suadicani, De PinaBenabou, Urban-Maldonado, Spray, \& Scemes, 2003; Theis et al., 2003). Previously used inhibitors have poor selectivity for different $C x$ species, affect both HCs and GJCs, and have significant effects on other targets (e.g., pannexin HCs and voltage-gated $\mathrm{Ca}^{2+}$ channels; Carlen, 2012; Hervé \& Sarrouilhe, 2005; Jin \& Chen, 2011; Nielsen et al., 2017; Willebrords, Maes, Crespo Yanguas, \& Vinken, 2017).

To explore the role of Cx43 HCs in seizures, we used TAT-Gap19 to block HC function without reducing GJCC via Cx43-based channels (Abudara et al., 2014). Gap19 is a synthetic nonapeptide derived from the intracellular L2 domain of Cx43 and specifically disturbs intramolecular interactions between the cytoplasmic loop (CL) and the carboxyterminal tail (CT) (Wang et al., 2013a; Figure1). These loop-tail interactions distinctly affect $\mathrm{C} \times 43 \mathrm{HCs}$ and GJCs, with GJCs being closed by these interactions, while HCs need these interactions to become available to open with electrical or chemical triggers (Wang et al., 2013b, Iyyathurai et al., 2013; reviewed in Leybaert et al., 2017). Gap19 has been demonstrated to inhibit Cx43 HCs while having no effect on Cx40 HCs, pannexin1 channels (Wang et al., 2013a) and Cx43 GJs (Abudara et al., 2014). The peptide targets and interacts with a sequence on the intracellular C-terminal domain, which is indeed very different between distinct Cxs, while the extracellular regions (e.g., targeted by Gap26, Gap27) are very well conserved (Wang et al., 2013a). As a result, Gap19 has intrinsically less chance of interacting with Cxs other than Cx43.

In the present study, we first performed in vitro mechanistic experiments in hippocampal slices demonstrating that the chemoconvulsant pilocarpine induces astroglial $\mathrm{C} \times 43 \mathrm{HC}$ opening which was blocked by the Cx43 HC inhibitor TAT-Gap19. Next, we carried out in vivo experiments to assess the effect of TAT-Gap19 on pilocarpineinduced limbic seizures and gliotransmitter release. Finally, we further explored the therapeutic potential of $\mathrm{C} \times 43 \mathrm{HC}$ inhibition in an acute and chronic electrical seizure mouse model of refractory seizures.

\section{MATERIALS AND METHODS}

\section{$2.1 \mid$ Animals}

Animals were housed at constant temperature $\left(21^{\circ} \mathrm{C} \pm 3^{\circ} \mathrm{C}\right) /$ relative humidity $(55 \% \pm 10 \%)$ in a $12 / 12 \mathrm{hr}$ light/dark cycle with free access to food and water. All efforts were made to minimize the number of animals used, their suffering and results are reported in accordance 
TABLE 1 Overview of the different peptides used in this study

\begin{tabular}{ll}
\hline Peptide & Amino acid sequence \\
\hline TAT & YGRKKRRQRRR \\
\hline TAT-Gap19 & YGRKKRRQRRR-KQIEIKKFK \\
\hline TAT-Gap19I130A & YGRKKRRQRRR-KQAEIKKFK \\
\hline Scrambled TAT-Gap19 & YGRKKRRQRRR-IEKFKIKQK \\
\hline
\end{tabular}

with the ARRIVE guidelines (Kilkenny, Browne, Cuthill, Emerson, \& Altman, 2010).

Acute brain slices were obtained from 2-month-old GFAP-eGFP transgenic mice of either sex, generated in the SPF animal facility of Collège de France. In these mice, astrocytes are labeled by the enhanced green fluorescent protein (eGFP) under the control of the human glial fibrillary acidic protein (GFAP) promotor, to be able to visualize astrocytes by direct fluorescence microscopy (Nolte et al., 2001). Experiments were performed according to the European Community Council Directives (2010/63/EU).

In vivo experiments were performed on male NMRI mice weighing 20-30 g and male Wistar rats weighing 250-300 g at time of surgery (Charles River Laboratories, Châtillon-sur-Chalaronne, France). Animals acclimatized at least 1 week to the animal facility and 1 day to the experimental room before being used in experiments. All procedures were carried out in accordance with the National Rules on Animal Experiments and were approved by the Ethical Committee for Animal Experiments of the Vrije Universiteit Brussel, Belgium.

\section{2 | Experimental design}

Slices or animals were randomly assigned to an experimental group and results were obtained as follows: automated software was used for dye uptake experiments and liquid chromatography analyses. For the focal pilocarpine mouse model, total seizure duration (depicted on electroencephalographic (ECoG) recordings) was counted blinded to treatment. For the focal pilocarpine rat model and acute $6 \mathrm{~Hz}$ mouse model, syringes were coded by another experimenter. As experiments cannot be performed blinded in the $6 \mathrm{~Hz}$ corneal kindling model, behavior was scored by two independent experimenters. Sample size was determined $a$ priori based on previous experience with the models.

\subsection{Connexin inhibitors and control peptides}

Carbenoxolone (CBX; MW 614.72 g/mol, Sigma-Aldrich, Steinheim, Germany), a glycyrrhetinic acid derivate, was used as a non-selective Cx channel inhibitor (positive control). TAT-Gap19 (MW 2703 Da), TAT-Gap19I130A, scrambled TAT-Gap19 and TAT (MW 1560 Da) were synthesized by Pepnome Inc. (Hong Kong, China, >95\% purity) or Genosphere Biotechnologies (Paris, France, $>95 \%$ purity; Table 1). TAT-Gap19 was used as a Cx43 HC inhibitor. Gap19 was coupled to the transactivator of transcription (TAT)-sequence of the HIV-1 virus to increase its cell membrane permeability, as the CT target is intracellularly located (Wang et al., 2013a). Three different negative control peptides were used throughout the experiments. (a) TAT-Gap19I130A, an I130A-modified Gap19 analogue, was chosen since amino acid I130 is involved in the formation of hydrogen bonds and thereby important for Gap19 activity. This mutant was demonstrated to have no effects on Cx43 HCs (Wang et al., 2013a). (b) Additionally, a scrambled version of TAT-Gap19 (i.e., scrambled TAT-Gap19) was used as a control peptide. (c) To rule out effects due to the cell-penetrating TAT linker, TAT was also subjected to several models.

Compounds were freshly dissolved in oxygenated artificial cerebrospinal fluid (aCSF) (for acute brain slice experiments), $0.1 \mathrm{M}$ phosphate buffered saline (PBS; Sigma-Aldrich, Steinheim, Germany; for intracerebroventricular (i.c.v.) administration), saline (0.9\% $\mathrm{NaCl}$, Baxter, Lessines, Belgium; for intraperitoneal (i.p.) administration) or modified Ringer's solution (for intrahippocampal administration). Doses and treatment time intervals were based on literature data (Abudara et al., 2014; Chever, Lee, et al., 2014; Walrave et al., 2016; Wang et al., 2013a) or dose-response studies (data not shown).

\subsection{Ethidium bromide uptake experiments in acute brain slices}

GFAP-eGFP mice were sacrificed by cervical dislocation, decapitated and their brains were dissected and placed in ice-cold slicing medium containing (in mM) glucose (10.00), sucrose (222.00), $\mathrm{NaHCO}_{3}$ (27.00), $\mathrm{KCl}$ (2.60), $\mathrm{NaH}_{2} \mathrm{PO}_{4} \cdot \mathrm{H}_{2} \mathrm{O}$ (1.25), $\mathrm{MgSO}_{4} .7 \mathrm{H}_{2} \mathrm{O}$ (7.00), ascorbic acid (0.10), $\mathrm{CaCl}_{2} \cdot 2 \mathrm{H}_{2} \mathrm{O}$ (0.50); bubbled with $95 \% \mathrm{O}_{2} / 5 \% \mathrm{CO}_{2}$ (290$300 \mathrm{mOsm})$. Coronal brain hemisphere slices $(300 \mu \mathrm{m})$ were cut on a vibroslicer (Microm HM 650 V, Thermo Scientific, Walldorf, Germany) and transferred to a nylon mesh submerged in oxygenated aCSF. Slices were incubated $30 \mathrm{~min}$ at $32^{\circ} \mathrm{C}$ and $30 \mathrm{~min}$ at room temperature (RT). The aCSF solution contained (in $\mathrm{mM}$ ) $\mathrm{NaCl}$ (125.00), $\mathrm{KCl}(2.50)$, $\mathrm{NaH}_{2} \mathrm{PO}_{4} \cdot \mathrm{H}_{2} \mathrm{O}$ (1.25), $\mathrm{NaHCO}_{3}$ (25.00), glucose (25.00), $\mathrm{MgCl}_{2}$ (1.00), and $\mathrm{CaCl}_{2} \cdot 2 \mathrm{H}_{2} \mathrm{O}$ (2.00) (300-320 mOsm).

Acute brain slices were incubated with oxygenated aCSF with or without inhibitor (CBX, TAT-Gap19) or negative control peptide (here TAT and scrambled TAT-Gap19). Since the lack of effect with $100 \mu \mathrm{M}$ TAT-Gap19 (Wang et al., 2013a) in our first slice experiments $(n=3)$, we opted to use $200 \mu \mathrm{M}$ inhibitor for the remainder of the experiments.

Pilocarpine (15 $\mu \mathrm{M}$, Sigma-Aldrich, Steinheim, Germany) was added to the incubation chambers (except for control condition) and slices were treated for $40 \mathrm{~min}$ to trigger $\mathrm{HC}$ activity in astrocytes. The test conditions included: (a) control where slices were only exposed to aCSF (Ctr), (b) 40 min exposure to pilocarpine alone (P40), and exposure to (c) CBX, (d) TAT-Gap19, (e) TAT, or (f) scrambled TAT-Gap19 (all $200 \mu \mathrm{M}$ ), $15 \mathrm{~min}$ before and during pilocarpine treatment (i.e., $\mathrm{CBX}+\mathrm{P} 40$, TG19 + P40, TAT + P40, scrTG19 + P40, respectively). Next, the HC permeable fluorescent tracer ethidium bromide $(\mathrm{EtBr} ; 4 \mu \mathrm{M}$, SigmaAldrich, Steinheim, Germany) was incubated for $10 \mathrm{~min}$ at RT as previously described (Giaume, Orellana, Abudara, \& Sáez, 2012). Finally, slices were rinsed for $15 \mathrm{~min}$ in aCSF to stop dye uptake and reduce background labeling. Slices were submerged for $40 \mathrm{~min}$ in fixing solution (4\% paraformaldehyde in PBS) and rinsed in PBS before mounting in Fluoromount-G mounting medium (Southern Biotechnology Associates, Inc., Birmingham, USA). At least six images covering the interpyramidal 
zone of the CA1 to CA3 hippocampus were captured for each experimental condition with a 40X objective using a confocal laser-scanning microscope (Leica TCS SP5, Leica, Wetzlar, Germany). Stacks of 22 consecutive confocal images at $0.49 \mu \mathrm{m}$ intervals were acquired sequentially with two different laser wavelengths (argon $488 \mathrm{~nm}$ for eGFP and $561 \mathrm{~nm}$ for EtBr). Images were processed with Image J (Fiji; National Institutes of Health (NIH) software; Schindelin et al., 2012) with a macro for automated analysis. All cells that were eGFP-positive were identified as astrocytes and $\mathrm{EtBr}$ fluorescence intensity was then measured within these eGFP-positive cells. Fluorescence was quantified in arbitrary units and $\mathrm{EtBr}$ uptake intensity was evaluated as the difference between the fluorescence from astrocytes (at least 20-30 cells per image) and background fluorescence measured in the same field where no labeled cells were detected. Averages of all eGFP-positive cells of at least six images were calculated as the final measurement of dye uptake in that condition. Finally, the $\mathrm{EtBr}$ uptake in each condition was normalized to the concurrent control condition for graphic representation of the data.

\section{5 | Surgery}

All animals received $4 \mathrm{mg} / \mathrm{kg}$ ketoprofen (Ketofen, Merial, Toulouse, France) subcutaneously (s.c.) before surgery to prevent post-operative pain and inflammation.

For the pilocarpine mouse model (intrahippocampal administration), a microdialysis guide (MAB6.10.IC, Microbiotech/se AB, Stockholm, Sweden) was implanted $2 \mathrm{~mm}$ above the left hippocampus (from bregma, mm: anterior-posterior (AP) - 2.70, medial-lateral $(\mathrm{ML})+3.0$; and -1.5 below dura mater) under $2.5 \%-3 \%$ isoflurane anesthesia (Isovet, Dechra Veterinary Products, Bladel, The Netherlands). Additionally, mice were s.c. implanted with a sterilized (Actril Cold Sterilant, Medivators B.V., Heerlen, The Netherlands) radiotelemetric mouse transmitter (DSI PhysioTel ETA-F10; Data Sciences International, Tilburg, The Netherlands) to assess seizure severity. By means of stainless steel screws, the measuring electrode was positioned above the right hippocampus (contralateral site of microdialysis guide) and the reference electrode above the cerebellum (AP - $1 \mathrm{~mm}$ according to lambda). The guide and electrodes were fixated with dental cement. After transmitter implantation, 4 mg/kg enrofloxacin s.c. (Baytril, Bayer, Diegem, Belgium) was given to prevent bacterial infections.

For the acute $6 \mathrm{~Hz}$ seizure mouse model (i.c.v. administration), a guide cannula ( $3 \mathrm{~mm}, 26 \mathrm{GA}$, Bilaney Consultants, Düsseldorf, Germany) was implanted stereotactically in the left brain ventricle (from bregma, mm: AP - 0.34, ML + 1, dorso-ventral (DV) - 2.20). The mice were single-housed to avoid cannulated mice from chewing on each other's cannulas and were allowed to recover for 7 days. A stylus (Bilaney Consultants, Düsseldorf, Germany) was placed inside the guide cannula to preclude clogging.

Wistar rats were anesthetized with a mixture of ketamine:diazepam (start dose 90.5:4.5 mg/kg i.p.; ketamine 1000 Ceva, Ceva Sante Animale; Valium, Roche, both Brussels, Belgium). A microdialysis guide (MAB6.14.IC, Microbiotech/se AB, Stockholm, Sweden) was implanted stereotactically above the left hippocampus (from bregma, mm: AP 5.6, $\mathrm{ML}+4.6$; and -4.6 below dura mater). Two anchor screws were placed in the skull and dental cement was applied to fixate the guide cannula to the skull.

After surgery, mice and rats received 1 or $5 \mathrm{ml}$ saline i.p. respectively to prevent dehydration and were placed in front of an infrared lamp or on a heating mat for 15 min to safely raise core body temperature. At the end of the experiments, animals were sacrificed with 200 mg/kg sodium pentobarbital (Nembutal, Ceva Santé Animale, Libourne, France) and accuracy of guide implantation was verified postmortem and compared against an anatomic atlas (Paxinos \& Franklin, 2004; Paxinos \& Watson, 2005).

\subsection{Focal pilocarpine model in mice}

After removing the inner guide cannula, an MAB6.10.2 probe $(2 \mathrm{~mm}$ membrane, 15 kDa cut-off, Microbiotech/se AB, Stockholm, Sweden) was inserted and probes were continuously perfused with modified Ringer's solution containing (in $\mathrm{mM}$ ) $\mathrm{NaCl}$ (147), $\mathrm{KCl}$ (4) and $\mathrm{CaCl}_{2} \cdot 6 \mathrm{H}_{2} \mathrm{O}$ (2.3), at a flow rate of $2 \mu \mathrm{l} / \mathrm{min}$ (CMA 400 Syringe Pump, CMA Microdialysis, Kista, Sweden). The animals recovered overnight in their microdialysis cage and all experiments in freely-moving mice started the next day. Each experiment started with modified Ringer's solution perfusion for $60 \mathrm{~min}$ (baseline conditions). In the pretreatment protocol, this was followed by a 60 min pretreatment period with vehicle, scrambled TAT-Gap19 or TAT-Gap19. Next, seizures were evoked by intrahippocampal pilocarpine perfusion ( $12 \mathrm{mM}, 40 \mathrm{~min}$ ) in the presence of vehicle, scrambled TAT-Gap19 or TAT-Gap19. Perfusion of vehicle or peptides lasted until the end of the experiment (for another $100 \mathrm{~min}$ ) (detailed protocol in Figure 3 upper panel). In a subset of mice, dialysate samples were collected every $10 \mathrm{~min}$ and analyzed for D-serine levels via an enantioselective high-performance liquid chromatography (HPLC) method described in Section 2.10.

In a second set of experiments, we investigated the possible attenuation of D-serine levels as a part of the anticonvulsant action of TAT-Gap19. Therefore, we used a similar microdialysis protocol as described above, but now administered a high dose of D-serine (600 mg/kg i.p., Sigma-Aldrich, Steinheim, Germany) 20 min before TAT-Gap19 perfusion. Next, i.p. injections of $300 \mathrm{mg} / \mathrm{kg}$ D-serine were repeated every hour until the end of the experiment (detailed protocol in Figure $4 b$ upper panel). This dose of $D$-serine is similar to the one used in several studies (Duffy, Labrie, \& Roder, 2008; Gómez-Galán et al., 2013; Seif et al., 2015) and adopted to replenish extracellular Dserine levels. The dose-regimen rationale was based on the half-life of D-serine in mice (i.e., $t_{1 / 2} \sim 1 \mathrm{hr}$; Rais et al., 2012).

Moreover, to investigate whether $\mathrm{C} \times 43 \mathrm{HC}$ inhibition can interrupt ongoing seizure activity, additional microdialysis experiments were performed in which TAT-Gap19 was administered 20 min after the occurrence of pilocarpine-induced seizures (post-onset), lasting until the end of the experiment (detailed protocol in Supporting Information Figure S2, upper panel).

ECoG monitoring was used to measure seizure duration in each mouse. Mice implanted with a radiotelemetric transmitter were placed in a video-ECoG monitoring unit equipped with a radiotelemetric receiver (PhysioTel Receiver Model RPC-1; Data Sciences International, 
Tilburg, The Netherlands) coupled to the Notocord-hem Evolution acquisition software (Notocord, Croissy-sur-Seine, France). During the microdialysis experiment, the ECoG was sampled with a frequency of $100 \mathrm{~Hz}$ and total seizure duration was calculated as the sum of the duration of all individual seizures by a scientist blinded to treatment. Calculation of one seizure started from the time of identifiable change of ECoG activity to the end of ictal ECoG activity and these changes had to last for minimum $5 \mathrm{~s}$. Two consecutive seizures were counted as one seizure when they were separated with less than $30 \mathrm{~s}$.

\section{7 | Focal pilocarpine model in rats}

The in vivo microdialysis pretreatment protocol in freely-moving rats was similar to the one described above in mice. We however used an MAB6.14.3 probe (3 mm membrane length, 15 kDa cut-off, Microbiotech/se AB, Stockholm, Sweden). The detailed protocol is given in Figure 5, upper panel.

Since rats show typical seizure-related behavioral changes in this model, a modified Racine's scale was used to score seizure severity with stages (0) normal, non-epileptic behavior, (1) mouth and facial movements, hyperactivity, excessive grooming, sniffing, scratching, wet dog shakes, (2) head-nodding, staring, tremor, (3) forelimb clonus/ extension, (4) rearing, salivating, tonic-clonic activity and (5) falling (Racine, 1972). This scale was previously validated by our research group by ECoG monitoring (Meurs, Clinckers, Ebinger, Michotte, \& Smolders, 2008). For every $20 \mathrm{~min}$, the highest seizure severity score (SSS) was assigned, starting from pilocarpine perfusion until the end of the experiment (in total $140 \mathrm{~min}$ or seven collection periods). The total seizure severity score (TSSS) for each animal is calculated as the sum of these seven SSSs and was used as a measure of seizure severity.

\subsection{Acute $6 \mathrm{~Hz}$ mouse model of refractory seizures}

Limbic psychomotor seizures were evoked via corneal stimulation $(6 \mathrm{~Hz}$, $0.2 \mathrm{~ms}$ rectangular pulse width, $3 \mathrm{~s}$ duration) using an ECT Unit 57800 stimulator (Ugo Basile, Varese, Italy). All experiments were performed at a current intensity of $49 \mathrm{~mA}$, found to be optimal in a current-response study (Walrave et al., 2015). A drop of 0.5\% xylocaine (AstraZeneca, Brussels, Belgium) in saline was applied to the eyes to induce local anesthesia and ensure good conductivity. After stimulation, the animals were gently placed in an open plastic cage $(35 \times 55 \mathrm{~cm})$ to observe the presence or absence of seizure activity, which is characterized by stun, forelimb clonus and/or elevated Straub-tail. For each animal, the total seizure duration was manually recorded by a scientist blinded for treatment.

For the i.c.v. experiments, in which compounds are directly delivered into the ventricle, the stylus was removed from the guide cannula on the day of the experiment and a 33 GA injection cannula (Bilaney Consultants, Düsseldorf, Germany) was inserted through the guide cannula, extending $1 \mathrm{~mm}$ beyond its tip in the ventricle. TAT-Gap19, its inactive mutant peptide (TAT-Gap191130A), TAT (all $1 \mathrm{mM}$ solutions) or vehicle (PBS) was infused in the ventricle via the injection cannula for $2 \mathrm{~min}$ at a flow rate of $0.5 \mu \mathrm{l} / \mathrm{min}$ (total $1 \mu \mathrm{l}$; CMA 400 Syringe Pump, CMA Microdialysis, Kista, Sweden), 60 min prior to the corneal stimulation. Following drug infusion, injection cannulas were left in place for 1 min to allow drug diffusion away from the cannula tip. Thus, mice received either $2.7 \mu \mathrm{g} / \mu \mathrm{l}(1 \mathrm{nmol} / \mu \mathrm{l})$ TAT-Gap19, $2.7 \mu \mathrm{g} / \mu \mathrm{l}$ $(1 \mathrm{nmol} / \mu \mathrm{l})$ TAT-Gap19l130A, $1.56 \mu \mathrm{g} / \mu \mathrm{l}(1 \mathrm{nmol} / \mu \mathrm{l})$ TAT or $1 \mu \mathrm{l} \mathrm{PBS} \mathrm{i}$. c.v. We previously demonstrated TAT-Gap19 diffusion from ventricle to hippocampus (Walrave et al., 2016).

For the i.p. experiments, $25 \mathrm{mg} / \mathrm{kg}$ TAT-Gap19, its inactive scrambled version $(25 \mathrm{mg} / \mathrm{kg}$ scrambled TAT-Gap19) or vehicle $(0.9 \%$ $\mathrm{NaCl})$ was administered 60 min prior to the corneal stimulation.

\section{9 | Chronic $6 \mathrm{~Hz}$ corneal kindling mouse model}

Initially, we explored different current intensities, applied once, to find a subconvulsive current intensity in male NMRI mice (i.e., $19 \mathrm{~mA}$, data not shown). These animals were not included in the actual kindling experiment.

Mice were stimulated twice daily (between 8-10 hr and 14-16 hr, Monday to Friday) at a fixed, initially subconvulsive threshold current (19 mA, 0.2 ms monopolar pulses, 6 Hz, 3 s; ECT Unit 57800, Ugo Basile, Varese, Italy) via corneal electrodes until reaching the fully kindled state (i.e., displaying 10 consecutive generalized seizures; acquisition phase). Prior to each stimulation, 0.5\% xylocaine (AstraZeneca, Brussels, Belgium) was applied to the eyes. After stimulation, mice were immediately placed in a plastic cage and observed until the end of the seizure. A modified Racine's scale was used to score kindlinginduced behavioral changes with stages (0) normal, non-epileptic behavior, (1) facial twitches and chewing, (2) head-nodding, (2,5) unilateral forelimb clonus, (3) bilateral forelimb clonus, (4) rearing with forelimb clonus and (5) generalized clonus with rearing and falling (Coppens et al., 2016). At the beginning, mice develop focal seizures (Stages 1 and 2), which evolve to generalized seizures (Stages 3-5) due to repeated subconvulsive stimulations. Mice that reached the fully kindled state were only stimulated twice a week (Monday/Thursday or Tuesday/Friday; maintenance phase). After maximum 5 weeks of stimulation, all non-kindled animals were discarded.

To test the anticonvulsant effect of TAT-Gap19 in fully-kindled mice, animals were stimulated on Monday morning without any intervention (STIM 1), on Monday afternoon with vehicle $(0.9 \% \mathrm{NaCl}$ i.p., 60 min prior to stimulation; STIM 2), on Tuesday morning without any intervention (STIM 3) and on Tuesday afternoon with TAT-Gap19 (25 or $50 \mathrm{mg} / \mathrm{kg}$ i.p., $60 \mathrm{~min}$ before stimulation; STIM 4).

Fully-kindled animals that exhibited a generalized seizure (Stages 3-5) both after vehicle (STIM 2) and morning stimulation (STIM 3) were included in the experiments. All fully-kindled animals used in the experiments met these criteria (100\% inclusion rate). Seizure severity was assessed by two independent experimenters and scores following vehicle and TAT-Gap19 administration were compared.

\subsection{Enantioselective liquid chromatography method for $D$-serine analysis}

D-serine levels were measured in the dialysates which were obtained in the focal pilocarpine mouse model (pretreatment protocol) using an HPLC system (Shimadzu, Duisberg, Germany) coupled with a spectrofluorimetric detector (Shimadzu), as described previously (Gómez-Galán 


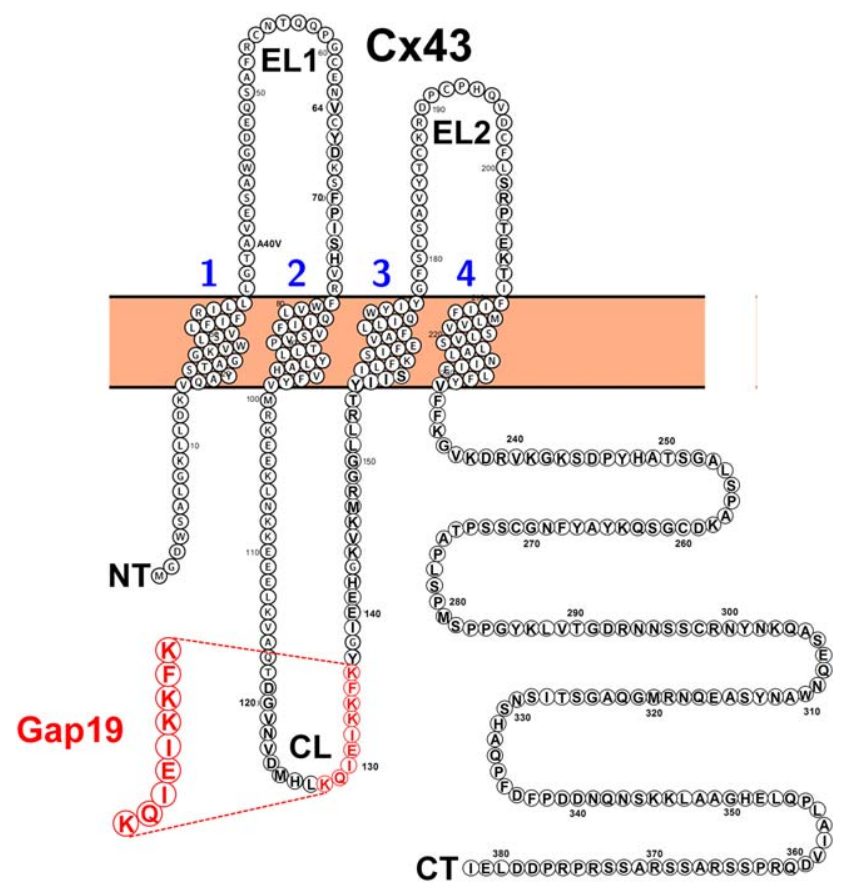

FIGURE 1 Position of the Gap19 sequence in the cytoplasmic loop (CL) domain of connexin43 (Cx43). Gap19 inhibits Cx43 hemichannel opening by interacting with the last nine amino acids of the carboxy-terminal tail (CT; Illustration generated with the Protter tool; Omasits, Ahrens, Müller, \& Wollscheid, 2014) [Color figure can be viewed at wileyonlinelibrary.com]

et al., 2013). Briefly, D-serine was separated on a Capcell Pak C18 type MH column (Shiseido, Tokyo, Japan) with $2 \mathrm{~mm}$ diameter and $250 \mathrm{~mm}$ length. $\mathrm{D}$-serine was eluted with gradient elution, by using mobile phase A (0.025 M Na $2 \mathrm{HPO}_{4} .12 \mathrm{H}_{2} \mathrm{O}, \mathrm{pH}$ 9) and mobile phase B (methanol: ultrapure water, 60:40 V/V; $0.17 \mathrm{ml} / \mathrm{min}$ ). Derivatisation was performed at $4^{\circ} \mathrm{C}$ by adding $9 \mu \mathrm{l}$ of the derivatisation mixture, containing ortho-phtalaldehyde and $\mathrm{N}$-isobutyryl-L-cysteine (both Sigma-Aldrich, Steinheim, Germany) to $9 \mu \mathrm{l}$ sample. Chromatograms were recorded with $340 \mathrm{~nm}$ excitation and $450 \mathrm{~nm}$ emission wavelengths and intregration was obtained with the Chromeleon software (ThermoScientific, Waltham, MA, USA). Standards (0, 0.25, 0.50, 0.75, and $1 \mu \mathrm{M})$ were made by spiking modified Ringer's solution with standard D-serine (Sigma-Aldrich, Steinheim, Germany).

\subsection{1 | Data analyses and statistics}

Statistical analyses were performed using GraphPad Prism 6.01 (GraphPad Software, Inc. La Jolla, CA) with $\alpha$ set at 0.05. Data are expressed as means \pm SEM. D'Agostino-Pearson omnibus normality test was used to verify data distribution. Two-sided $t$ test (normal data) or twosided Mann-Whitney test (non-normal data) was used to denote significant differences between two experimental groups. To compare three different groups, one-way ANOVA followed by Tukey's multiple comparisons post hoc test (normal data) or Kruskal-Wallis followed by a Dunn's multiple comparisons post hoc test (non-normal data) was used. To compare paired measurements (of non-normal or categorical data), two-sided Wilcoxon matched-pairs signed-rank test (WMS; two groups) or Friedman test (four groups) was used. When more than one variable was assessed, two-way ANOVA followed by Tukey's post hoc test was used. Fisher's exact test was used to compare number of generalized seizures in $6 \mathrm{~Hz}$ kindling experiment. The appropriate statistical test is denoted in the results section and figure legends.

\section{3 | RESULTS}

\section{1 | Pilocarpine induces $\mathrm{Cx} 43 \mathrm{HC}$ opening in astrocytes studied in acute brain slices}

The chemoconvulsant pilocarpine is widely used ex vivo to induce epileptiform activity in hippocampal slices (Curia, Longo, Biagini, Jones, \& Avoli, 2008; Marchi et al., 2007; Nagao, Alonso, \& Avoli, 1996; Portelli et al., 2012). We here investigated the effect of pilocarpine on astrocytic $\mathrm{HC}$ opening (measured via EtBr dye uptake) in the interpyramidal zone of the CA1/CA2/CA3 region of acute hippocampal slices from GFAP-eGFP mice. Pilocarpine (15 $\mu \mathrm{M}, 40 \mathrm{~min}$ ) induced astrocytic HC opening, as indicated by an on average twofold increase in $\mathrm{EtBr}$ signal in GFAP-positive astrocytes (P40: $211.50 \% \pm 20.10 \%$ of control, $n=14$, two-sided WMS, $p=.0001$ compared with Ctr; Figure 2a).

This effect was suppressed by CBX $(200 \mu \mathrm{M})$, a non-selective blocker that inhibits both $C x$ and pannexin channels at the concentration applied, suggesting that $\mathrm{EtBr}$ uptake occurred through $\mathrm{Cx} \mathrm{HCs}$ or pannexin channels (CBX + P40: $77.13 \% \pm 22.65 \%$ of control, $n=7$, two-sided WMS, $p=.0156$ compared with P40).

The pilocarpine-induced $\mathrm{EtBr}$ uptake in astrocytes was also significantly decreased by $200 \mu \mathrm{M}$ TAT-Gap19 (TG19 + P40: $140.20 \% \pm 12.06 \%$ of control, $n=8$, two-sided WMS, $p=.0078$ compared with P40). As TAT-Gap19 is a more specific Cx43 HC blocker, this suggests that substantial astrocytic dye uptake occurred through HCs composed of $\mathrm{Cx} 43$.

There were no significant differences between pilocarpine treated slices and slices that were pre-treated with each of the TAT-Gap19 control peptides, namely the TAT sequence alone (TAT + P40: $200.08 \% \pm 18.96 \%$ of control, $n=7, p=.4375$ compared with P40) and the scrambled version of TAT-Gap19 (scrTG19 + P40: $207.10 \% \pm 44.84 \%$ of control, $n=7, p=.5781$ compared with P40, both two-sided WMS). Importantly, TAT-Gap19 significantly decreased $\mathrm{EtBr}$ uptake compared with the control peptides (TAT + P40 and scrTG19 + P40 both $p=.0313$ compared with TG19 + P40, both twosided WMS). By contrast, the CBX and TAT-Gap19 condition did not significantly differ from the concurrent control condition (CBX $+\mathrm{P} 40$ $p=.2969$ and TG19 + P40 $p=.078$ compared with Ctr, both two-sided WMS). Representative images of EtBr uptake are depicted in Figure 2b.

\section{2 | Intrahippocampal TAT-Gap19 attenuates pilocarpine-induced seizures and accompanying increases in extracellular $D$-serine levels in mice}

Subsequently, TAT-Gap19 was tested in vivo in the focal pilocarpine model, in which pilocarpine is perfused in the hippocampus of rodents to evoke limbic seizures. In the pretreatment protocol in mice, TATGap19 is administered $60 \mathrm{~min}$ prior to seizure induction. No 
a

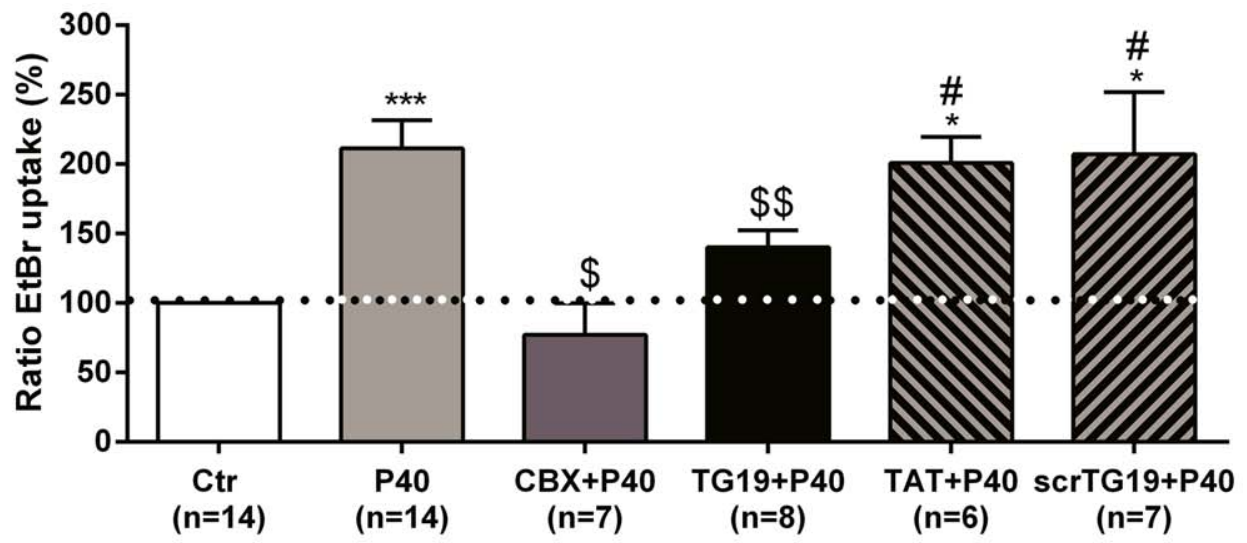

b
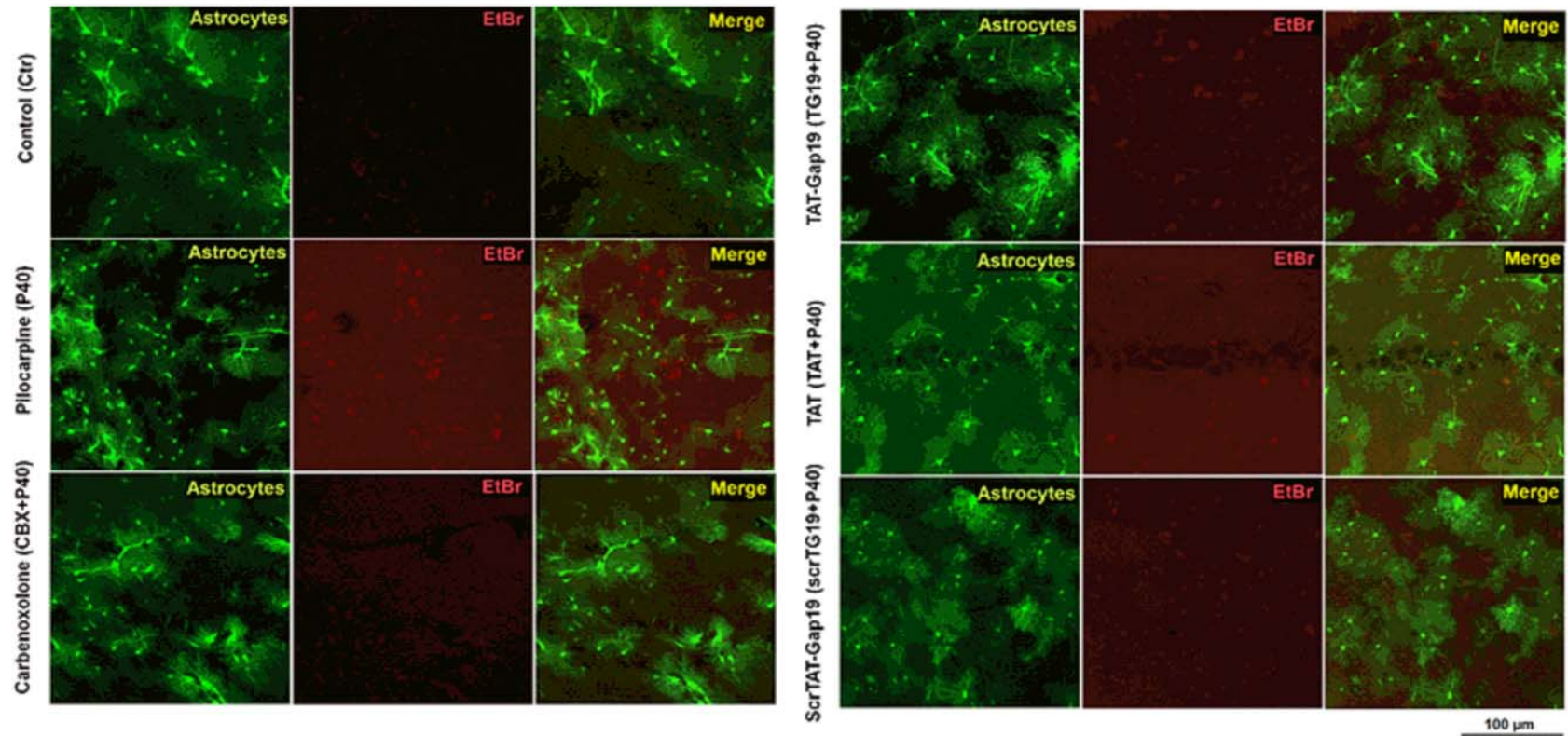

FIGURE 2 Pilocarpine treatment increases ethidium bromide (EtBr) uptake through astrocytic hemichannels (HCs) in acute hippocampal slices. (a) Averaged data normalized to control (Ctr) (dashed line) of EtBr uptake in GFAP-eGFP positive hippocampal astrocytes treated for 40 min with pilocarpine $(15 \mu \mathrm{M})$ alone $(\mathrm{P} 40)$ and in presence of the non-selective $\mathrm{Cx} /$ pannexin channel inhibitor carbenoxolone

(CBX + P40), the Cx43 HC inhibitor TAT-Gap19 (TG19 + P40) and its two negative control peptides TAT (TAT + P40) and scrambled TATGap19 (scrTG19 + P40), all applied at $200 \mu \mathrm{M}, 15$ min before pilocarpine treatment and during dye uptake measurement. (b) Fluorescence representative images of acute hippocampal slices derived from GFAP-eGFP transgenic mice show GFAP-eGFP astrocytes (green) and EtBr uptake (red). Images of hippocampal astrocytes were taken from the CA1-CA3 interpyramidal zone. Statistics: (a) Two-sided Wilcoxon matched-pairs signed-rank test with ${ }^{* * *} p<.001,{ }^{*} p<.05$ : significant increase compared with Ctr; $\$ \$ p<.01$, $\$ p<.05$ : significant decrease compared with P40, \#p $<.05$ significant difference between TAT-Gap19 and control peptides

anticonvulsant effects were observed with $12.5 \mu \mathrm{M}$ TAT-Gap19 $(2,824 \pm 968 \mathrm{~s}, n=8)$, as total seizure duration did not significantly differ from control mice receiving vehicle (modified Ringer's solution, $4,520 \pm 579 \mathrm{~s}, n=14$, Kruskal-Wallis test $(H=2.439, p=.2953)$ followed by Dunn's post hoc test, $p=.4197$ ) or $12.5 \mu \mathrm{M}$ of the control peptide scrambled TAT-Gap19 $(4,453 \pm 1,211 \mathrm{~s}, n=7$, Dunn's test post hoc test, $p=.6542$; Figure 3 a).

Perfusion of $25 \mu \mathrm{M}$ TAT-Gap19 however led to a clear significant decrease of total seizure duration $(2,113 \pm 607 \mathrm{~s}, n=12)$ compared with mice receiving $25 \mu \mathrm{M}$ scrambled TAT-Gap19 (4,120 $\pm 569 \mathrm{~s}$, $n=14$, two-sided $t$ test, $t=2.411, p=.0239$; Figure $3 \mathrm{~b}$ ), although without changing the latency to first seizure $(1,888 \pm 538 \mathrm{~s}$ for scrambled peptide and 2,190 $\pm 693 \mathrm{~s}$ for TAT-Gap19 peptide; two-sided MannWhitney test, $U=81.00, p=.8885$, Supporting Information Figure S1). Noteworthy, total seizure duration in vehicle and scrambled TAT-Gap19 treated animals was similar. Representative in vivo ECoG recordings of a $25 \mu \mathrm{M}$ scrambled TAT-Gap19 and $25 \mu \mathrm{M}$ TAT-Gap19 treated mouse are depicted in Figure $3 c, d$. These results indicate that pretreatment with TAT-Gap19 is able to attenuate pilocarpine-induced seizures.

On the contrary, when TAT-Gap19 was administered 20 min after seizure onset, the total seizure duration from mice receiving $50 \mu \mathrm{M}$ TAT-Gap19 $(3,423 \pm 934 \mathrm{~s}, n=6)$ did not significantly differ from the control mice receiving vehicle $(3,743 \pm 813 \mathrm{~s}, n=6$, two-sided MannWhitney test, $U=14.00, p=.5714)$, implicating that $\mathrm{C} \times 43 \mathrm{HC}$ 


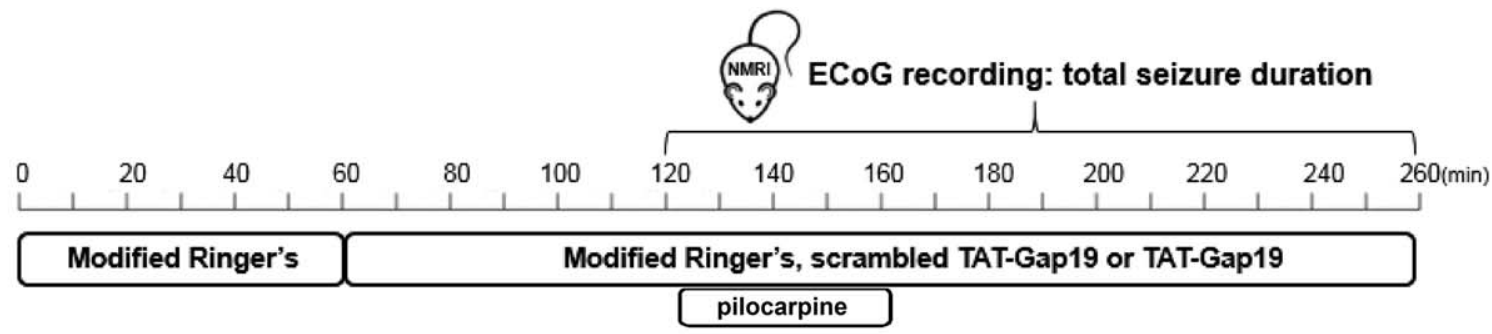

a

\section{b}

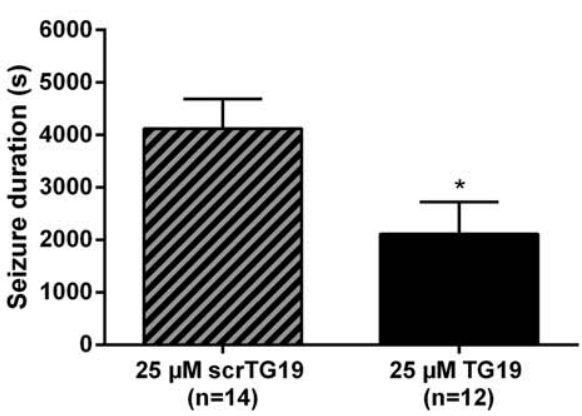

C

\begin{tabular}{|c|c|}
\hline Mod. Ringer's & $25 \mu \mathrm{M}$ scrambled TAT-Gap19 \\
\hline pilocarpine
\end{tabular}
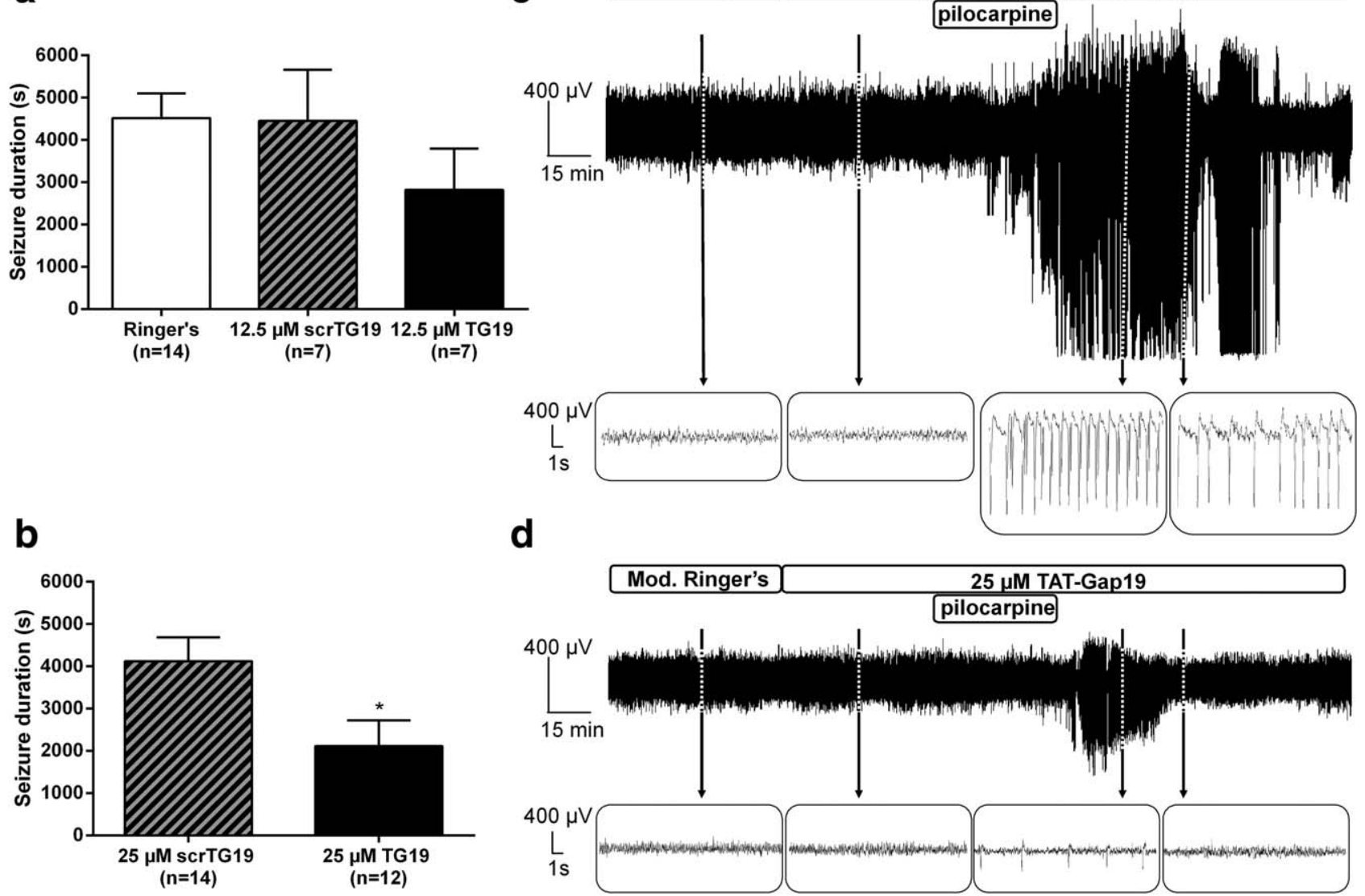

FIGURE 3 (a and b) Experimental microdialysis pretreatment protocol (upper panel) and dose-response experiments of TAT-Gap19 against pilocarpine-induced seizures in mice. Results are expressed as mean total seizure duration \pm SEM. (a) While $12.5 \mu$ M TAT-Gap19 (TG19, $n=7$ ) exerted no anticonvulsant effects compared with vehicle (modified Ringer's solution, $n=14$ ) or scrambled control peptide (12.5 $\mu M$ scrTG19, $n=7)$, (b) $25 \mu$ M TG19 ( $n=12)$ significantly decreased total seizure duration compared with scrambled control peptide $(25 \mu \mathrm{M}$ scrTG19, $n=12$ ). (c and d) Representative ECoG recordings of (c) a control experiment with $25 \mu M$ scrambled TAT-Gap19 (total seizure duration: 4,908 s) and (d) an experiment with $25 \mu \mathrm{M}$ TAT-Gap19 (total seizure duration: 1,890 s; movement artefacts were removed). Statistics: (a) Kruskal-Wallis with Dunn's multiple comparisons post hoc test and (b) Two-sided $t$ test with ${ }^{*} p<.05$

inhibition was unable to interrupt full-blown seizure activity (Supporting Information Figure S2).

To evaluate whether $\mathrm{Cx} 43 \mathrm{HCs}$ contribute to gliotransmitter release in vivo during seizures, $\mathrm{D}$-serine was analyzed in the microdialysis samples of a subset of mice receiving $25 \mu \mathrm{M}$ TAT-Gap19 and $25 \mu \mathrm{M}$ scrambled TAT-Gap19 (pretreatment protocol).

Since baseline D-serine dialysate levels were not different between scrambled TAT-Gap19 $(0.32 \pm 0.06 \mu \mathrm{M}, n=6)$ and TAT-Gap19 treated animals $(0.34 \pm 0.04 \mu \mathrm{M}, n=9$; two-sided Mann-Whitney test, $U=25.00, p=.8212$, data not shown), D-serine levels are expressed as a percentage of the baseline levels (Figure 4a). The average basal dialysate level was determined from the first six samples (60 min) prior to peptide administration. Next, data were transformed to the percent change in dialysate level compared with average baseline. A two-way ANOVA revealed an overall treatment effect meaning that $D$-serine levels were higher in the scrambled TAT-Gap19 group (116.7 $\pm 2.74 \%)$ compared with the TAT-Gap19 group (97.99 $\pm 1.91 \%$; Column Factor, $F(1,338)=19.69, p<.0001)$. This means that extracellular $D$-serine levels are increased during pilocarpine-induced seizures and that $\mathrm{C} \times 43 \mathrm{HC}$ inhibition is able to prevent this increase. We therefore suggest that Cx43 HCs, in a direct or indirect matter, facilitate D-serine release in vivo during seizures. 


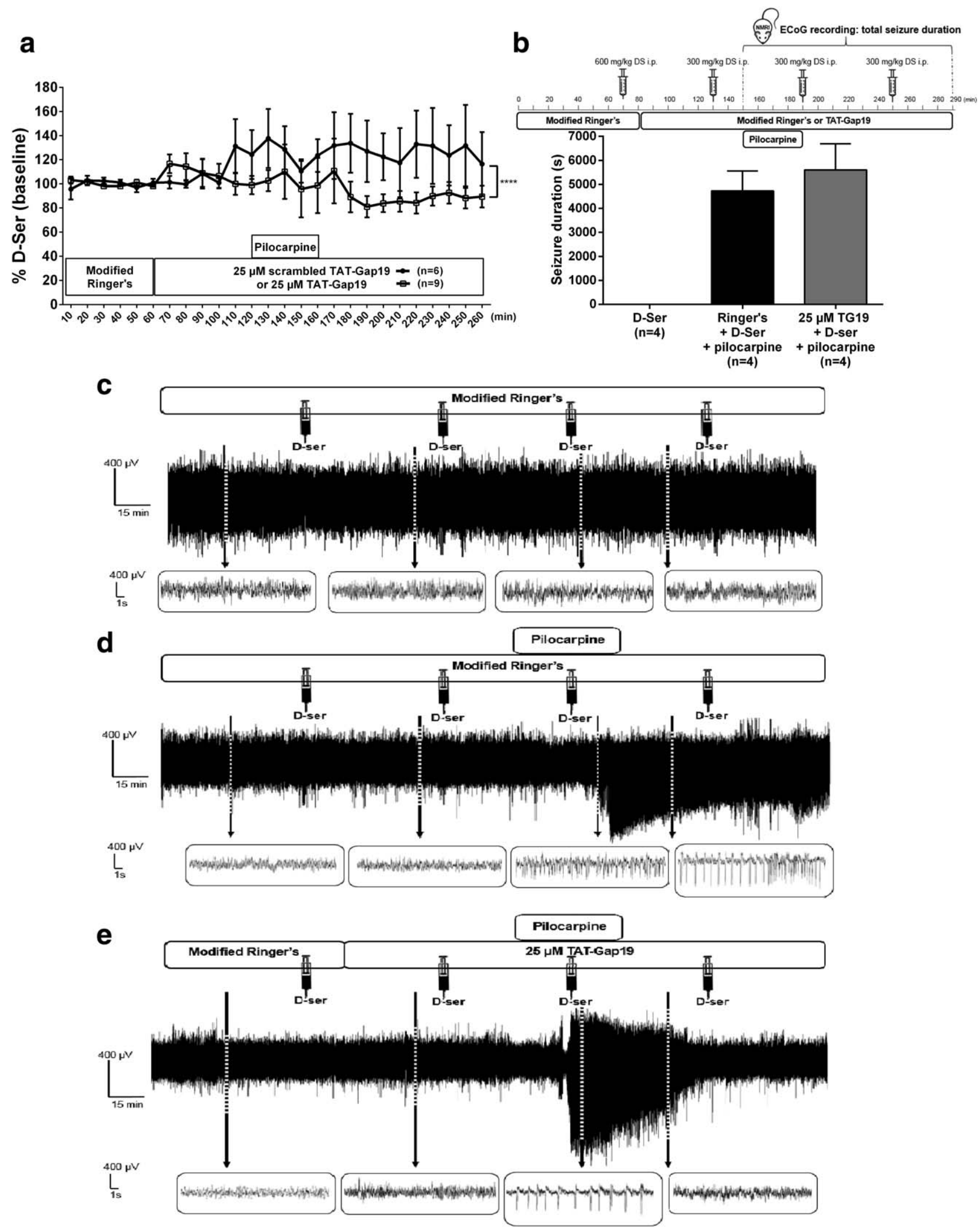

FIGURE 4. 


\subsection{The anticonvulsant action of TAT-Gap19 in the focal pilocarpine mouse model is abolished by exogenous D-serine}

We thus hypothesize that the attenuation of D-serine release might be involved in the anticonvulsant effect of TAT-Gap19. To test this hypothesis, additional microdialysis experiments were performed in which D-serine was co-administered with TAT-Gap19. Figure 4b shows the effect of D-serine co-administration on pilocarpine-induced seizures in a vehicle control group and a test group receiving $25 \mu \mathrm{M}$ TATGap19 (both $n=4$ ). The co-administration of D-serine completely abolished the anticonvulsant effect of $25 \mu \mathrm{M}$ TAT-Gap19 (total seizure duration vehicle: $4,726 \pm 834$ s vs. TAT-Gap19: 5,606 $\pm 1,089 \mathrm{~s}$, twosided Mann-Whitney test, $U=5.00, p=.4857$ ). Noteworthy, there were no seizures detectable on the ECoGs when $D$-serine was administered alone without pilocarpine (total seizure duration $0 \pm 0 s, n=4$ ). Respresentative ECoG recordings are depicted in Figure 4c-e.

\section{4 | Intrahippocampal TAT-Gap19 attenuates pilocarpine-induced seizures in rats}

We conducted the focal pilocarpine model in a different species (i.e., rats) to validate the anticonvulsant effect of TAT-Gap19 within this chemically-induced seizure model (pretreatment protocol). Following $12 \mathrm{mM}$ pilocarpine perfusion, control rats showed typical seizurerelated behavioral changes. An initial dose-response study was performed with $1 \mu \mathrm{M}(n=2), 12.5 \mu \mathrm{M}(n=2)$ and $200 \mu \mathrm{M}$ TAT-Gap19 $(n=2)$. Since 12.5 and $200 \mu M$ TAT-Gap19 showed anticonvulsant effects (data not shown), we pursued the experiments with the lowest anticonvulsant dose of $12.5 \mu \mathrm{M}$ TAT-Gap19. The mean TSSS \pm SEM for the vehicle group was $17.20 \pm 3.07(n=5)$, while the TSSS was significantly attenuated by perfusion of $12.5 \mu \mathrm{M}$ TAT-Gap19 (3.00 \pm 0.55 , $n=5$; two-sided Mann-Whitney test, $U=0.00, p=.0079$; Figure 5).

\subsection{TAT-Gap19 exerts anticonvulsant effects in the acute $6 \mathrm{~Hz}$ mouse model of refractory seizures after intracerebral and systemic administration}

To exclude that the anticonvulsant effects of TAT-Gap19 against pilocarpine-induced seizures are model-dependent, we next continued with compound testing in electrical models for seizures and epilepsy. Considering the need to test candidate drugs in models of
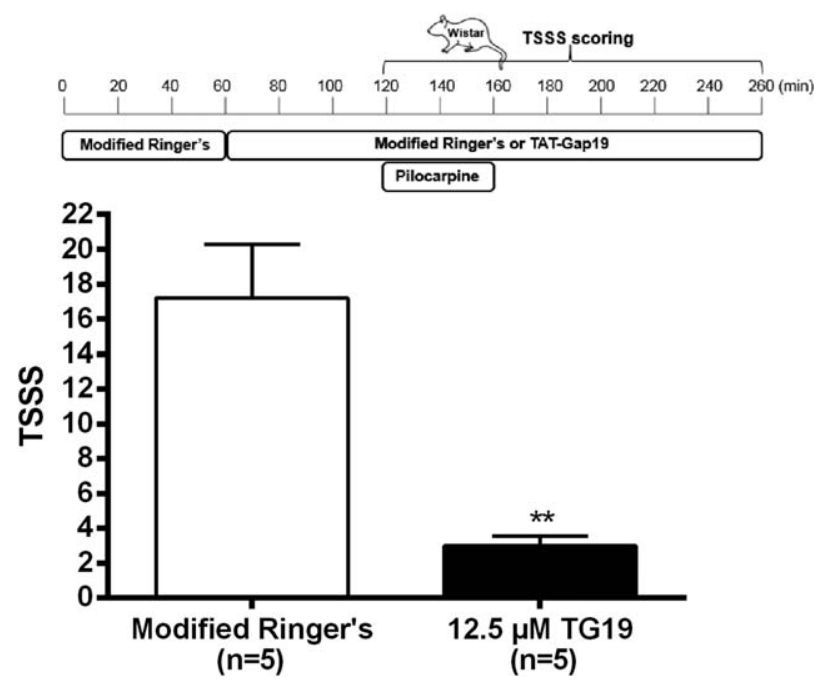

FIGURE 5 Experimental microdialysis pretreatment protocol (upper panel) and anticonvulsant effect of TAT-Gap19 against pilocarpine-induced seizures in rats. Results are expressed as mean total seizure severity score (TSSS) \pm SEM. The perfusion of $12.5 \mu \mathrm{M}$ TAT-Gap19 (TG19, $n=5$ ) significantly decreased TSSS compared with vehicle (modified Ringer's solution, $n=5$ ). Statistics: Two-sided Mann-Whitney test with ${ }^{* *} p<.01$

pharmacoresistant seizures, we investigated whether TAT-Gap19 shows effects in the acute $6 \mathrm{~Hz}$ mouse model of electrically-induced refractory seizures (Barton, Klein, Wolf, \& White, 2001; Walrave et al., 2015). Noteworthy, this model was recently added to the Epilepsy Therapy Screening Program (ETSP) of the National Institute of Neurological Disorders and Stroke (NINDS; Barker-Haliski et al., 2017).

Although TAT-Gap19 can be readily detected in brain tissue of mice following its peripheral administration (Abudara et al., 2014), we first investigated the local effect of TAT-Gap19 on $6 \mathrm{~Hz}$-evoked seizures. A one-way ANOVA ( $F=7.360, p=.0006)$ followed by Tukey's multiple comparisons post hoc test revealed that i.c.v. administered TAT-Gap19 significantly attenuated total seizure duration compared with vehicle i.c.v. (TAT-Gap19: $14 \pm 1 \mathrm{~s}, n=8$ vs. PBS: $33 \pm 5$ s, $n=10, p=.0048)$ and control peptides: 1 nmol TAT i.c.v. (38 $\pm 3 \mathrm{~s}$, $n=8, p=.0005)$ or 1 nmol TAT-Gap19I130A i.c.v. $(28 \pm 3 \mathrm{~s}, n=12$, $p=.0385)$. None of the control peptides exerted anticonvulsant effects (TAT vs. PBS $p=.7271$, TAT-Gap19I130A vs. PBS $p=.7323$; Figure 6a).

FIGURE 4 D-serine (D-Ser) involvement in the acute pilocarpine mouse model (pretreatment protocol). (a) Relative change in D-Ser concentration compared with baseline levels during peptide and pilocarpine administration. Results are expressed as percentage of mean basal release (\%D-Ser) \pm SEM. The solid circles denote D-Ser levels in microdialysates of $25 \mu \mathrm{M}$ scrambled TAT-Gap19 (scrTG19) treated animals $(n=6)$, while D-Ser levels of $25 \mu$ M TAT-Gap19 (TG19) treated animals $(n=9)$ are shown in open squares. (b) Experimental microdialysis pretreatment protocol (upper panel) and effect of co-administration of D-Ser together with $25 \mu \mathrm{M}$ TAT-Gap19 against pilocarpineinduced seizures in mice. Results are expressed as mean total seizure duration \pm SEM. Exogenous D-Ser abolished the anticonvulsant effects of TAT-Gap19, as no differences were found between vehicle (modified Ringer's solution, $n=4$ ) and TAT-Gap19 (TG19, $n=4$ ) treated animals. (c-e) Representative ECoG recordings of (c) an experiment with D-Ser alone (total seizure duration: 0 s), (d) a control experiment with vehicle and D-Ser co-administration (total seizure duration: 5,865 s) and (e) an experiment with $25 \mu \mathrm{M}$ TAT-Gap19 and D-Ser coadministration (total seizure duration: 5,488 s; movement and i.p. injection artefacts were removed). Statistics: (a) Two-way ANOVA with overall treatment effect ${ }^{* * *} p<.001$, (b) Two-sided Mann-Whitney test 

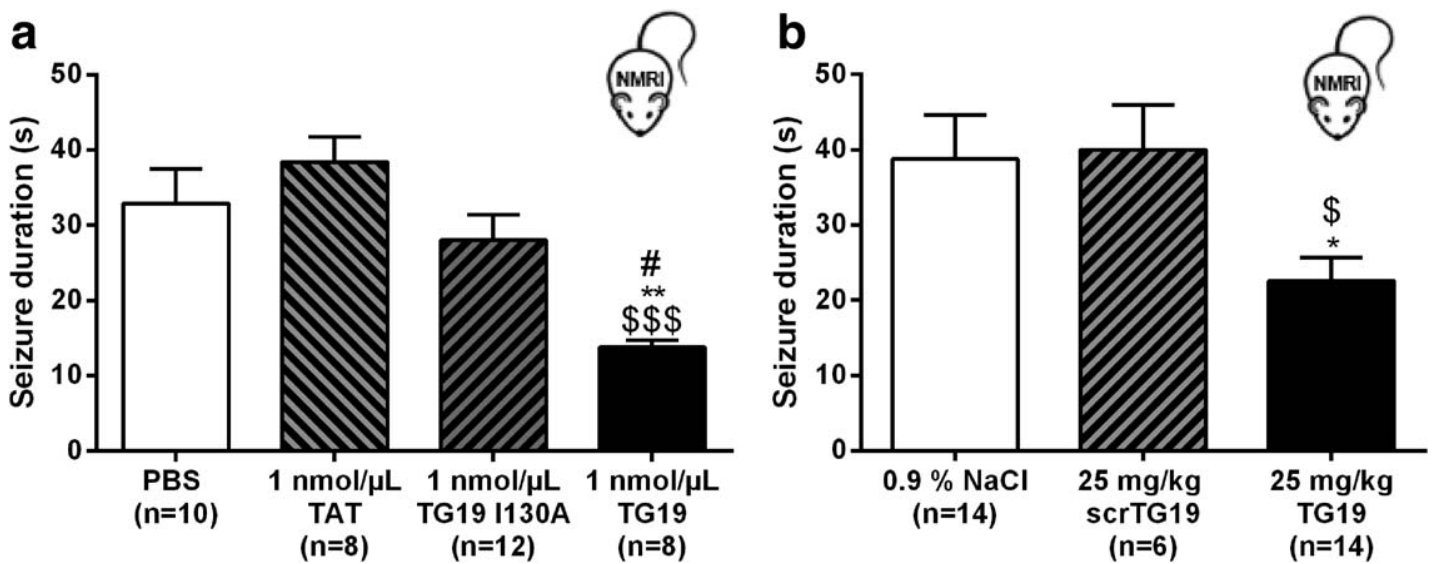

FIGURE 6 Effect of connexin43 hemichannel $(\mathrm{C} x 43 \mathrm{HC})$ inhibition in the acute $6 \mathrm{~Hz}$ mouse model of refractory seizures. Results are expressed as mean total seizure duration \pm SEM. (a) Locally administered TAT-Gap19 (TG19, $2.7 \mu \mathrm{g} / \mu$ l i.c.v., $n=8)$ significantly decreased total seizure duration compared with vehicle i.c.v. (PBS, $n=10), 1.56 \mu \mathrm{g} / \mu \mathrm{l} \mathrm{TAT} \mathrm{i.c.v.}(n=8)$ or $2.7 \mu \mathrm{g} / \mu \mathrm{l}$ TAT-Gap19I130A i.c.v.

(TG19I130A, $n=12$ ). (b) Systemically administered TAT-Gap19 (TG19, $25 \mathrm{mg} / \mathrm{kg}$ i.p., $n=14$ ) significantly decreased the total seizure duration compared with vehicle $(0.9 \% \mathrm{NaCl}, n=14)$ or scrambled TAT-Gap19 (scrTG19, $25 \mathrm{mg} / \mathrm{kg}$ i.p., $n=6)$. Statistics: (a) One-way ANOVA with Tukey's multiple comparisons post hoc test, with ${ }^{* *} p<.01$ compared with PBS, \$\$p <.001 compared with TAT and \#p $<.05$ compared with TG19I130A, (b) Kruskal-Wallis with Dunn's multiple comparisons post hoc test with * $p<.05$ compared with $0.9 \% \mathrm{NaCl}$ and $\$ p<.05$ compared with scrTG19

Since systemic administration is a more relevant delivery route, the effect of i.p. injected TAT-Gap19 on $6 \mathrm{~Hz}$-evoked refractory seizures was examined. A Kruskal-Wallis test $(H=9.212, p=.01)$ followed by Dunn's multiple comparisons post-hoc test shows that $25 \mathrm{mg} / \mathrm{kg}$ TATGap19 i.p. (23 \pm 3 s, $n=14)$ significantly attenuated total seizure duration compared with vehicle $(0.9 \% \mathrm{NaCl}$ i.p., $39 \pm 6 \mathrm{~s}, n=14$, $p=.0356)$ and control peptide $(25 \mathrm{mg} / \mathrm{kg}$ scrambled TAT-Gap19 i.p., $40 \pm 6 \mathrm{~s}, n=6, p=.0335)$. Total seizure duration was not altered in the scrambled TAT-Gap19 treated group compared with vehicle ( $p>$.9999; Figure 6b).

Decreasing the TAT-Gap19 dose to $15 \mathrm{mg} / \mathrm{kg}$ i.p. $(25 \pm 6 \mathrm{~s}, \mathrm{n}=7)$ however failed to significantly decrease seizure duration compared with vehicle $(0.9 \% \mathrm{NaCl}$ i.p., $44 \pm 8 \mathrm{~s}, n=8$, two-sided Mann-Whitney test, $U=12.00, p=.0718$, data not shown).

\subsection{TAT-Gap19 decreases seizure severity in the $6 \mathrm{~Hz}$ corneal kindling mouse model}

Next, TAT-Gap19 was evaluated in the chronic $6 \mathrm{~Hz}$ corneal kindling model, which is considered as a model of treatment-resistant epilepsy since partial seizures persist despite treatment with high doses of ASDs (Leclercq, Matagne, \& Kaminski, 2014).

Figure 7a illustrates kindling acquisition and demonstrates that within 4-5 weeks, mice reached the fully kindled state (i.e., exhibiting 10 consecutive generalized seizures). There was a clear progression in SSS from $1.10 \pm 0.36$ on the first day, to $4.10 \pm 0.22$ after 5 weeks of stimulations.

Fully kindled mice ( $n=16$ ) were used to investigate the possible anticonvulsant role of $\mathrm{Cx} 43 \mathrm{HC}$ inhibition in epileptic animals. The mean kindling scores of the animals (i.e., the mean SSS starting from being fully kindled until start of drug testing) did not differ from the scores obtained from the two morning stimulations (STIM 1 and STIM
3), nor from the vehicle score (STIM 2; for details see Section 2.9; Friedman test, $F=3.286, p=.3496$ for $25 \mathrm{mg} / \mathrm{kg}$ TAT-Gap19 experiment and $F=2.222, p=.5276$ for $50 \mathrm{mg} / \mathrm{kg}$ TAT-Gap19 experiment, Supporting Information Figure S3).

First, we tested $25 \mathrm{mg} / \mathrm{kg}$ TAT-Gap19 i.p. $(n=8)$, which is an anticonvulsant dose in the acute $6 \mathrm{~Hz}$ mouse model of refractory seizures. No statistical differences were observed between $25 \mathrm{mg} / \mathrm{kg}$ TATGap19 SSS (3.63 \pm 0.18$)$ and vehicle SSS $(4.25 \pm 0.25$, two-sided WMS, $p=.1250$ ) (Figure 7b).

A higher dose of TAT-Gap19 (50 mg/kg i.p., $n=16$ ) was examined in the other fully kindled animals $(n=8)$ and in the previously $25 \mathrm{mg}$ / kg TAT-Gap19 treated animals ( $n=8$ ), following an adequate washout period of 1 week. During this wash-out period, mice were stimulated twice daily for 2 days per week to maintain the kindled state and no change was seen on the seizure severity. At this dose, the TATGap19 SSS $(2.62 \pm 0.38)$ was significantly lower than vehicle SSS (3.87 \pm 0.20 , two-sided WMS, $p=.0129$; Figure 7c). Generalized seizures (Stages 3-5) occurred in all vehicle treated animals, while only half of the animals experienced a generalized seizure following $50 \mathrm{mg} / \mathrm{kg}$ TAT-Gap19, which was significantly different from each other (twosided Fisher's exact test, $p=.0024$, Figure 7d).

\section{4 | DISCUSSION}

We here tested whether Cx43 HC inhibition with TAT-Gap19 could influence seizure activity in in vivo rodent models. Various models were applied to that purpose, including focal microdialysis-delivered pilocarpine model in mice (scored by seizure duration, D-serine measurements) and rats (scored by TSSS), acute $6 \mathrm{~Hz}$ corneal stimulation (scored by seizure duration) and chronic $6 \mathrm{~Hz}$ corneal kindling (scored by SSS) in mice. In all models, pretreatment with TAT-Gap19 significantly 

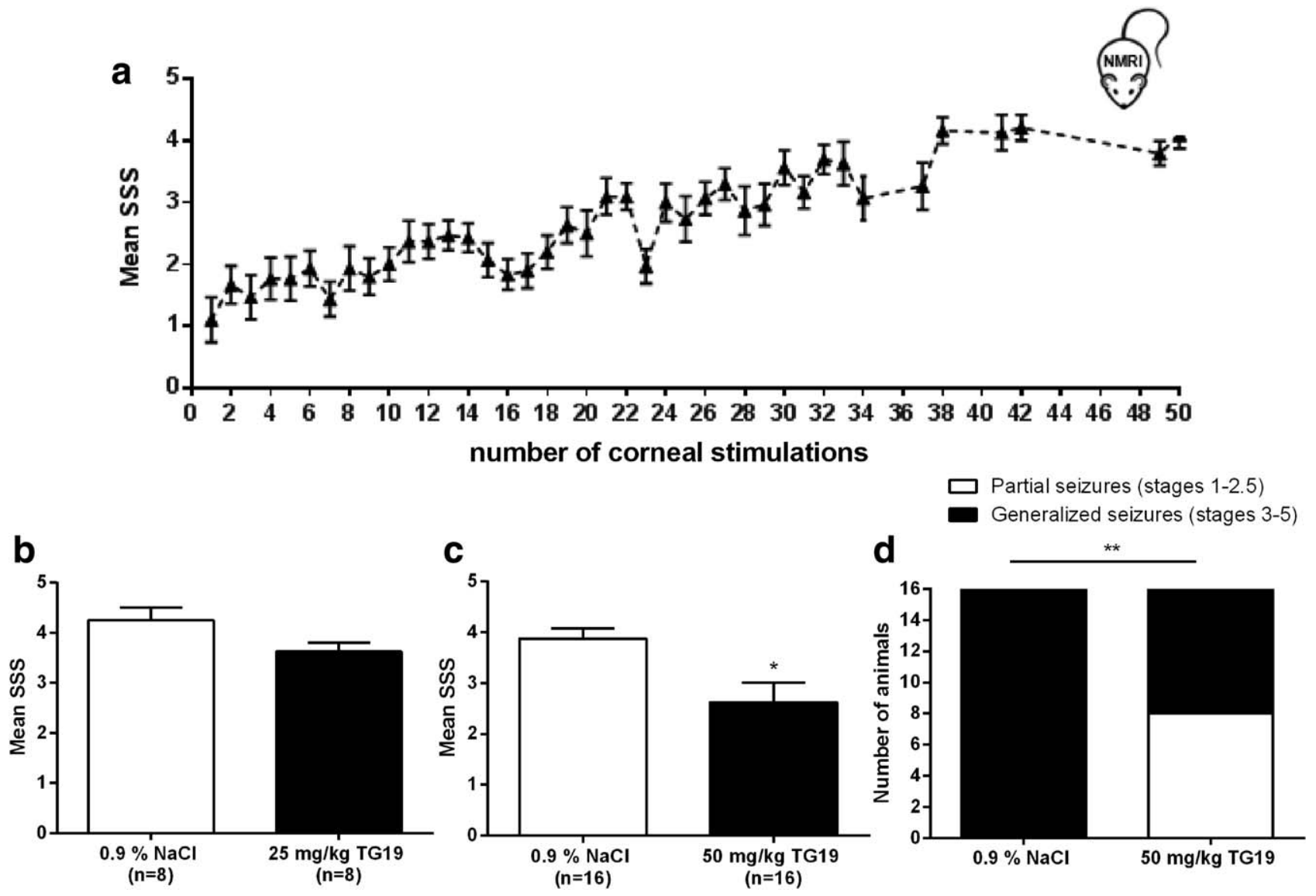

FIGURE $7 \quad 6 \mathrm{~Hz}$ corneal kindling in NMRI mice. (a) Kindling acquisition: mean seizure severity score (SSS) \pm SEM as a function of kindling stimulations. The mice were considered fully kindled when they displayed at least 10 consecutive generalized seizures (Stages 3-5). (b and c) Effect of systemically administered TAT-Gap19 (TG19) in the $6 \mathrm{~Hz}$ corneal kindling model with (b) effect of $25 \mathrm{mg} / \mathrm{kg}$ i.p. (n = 8) and (c) effect of $50 \mathrm{mg} / \mathrm{kg}$ i.p. $(n=16)$ on mean SSS \pm SEM in $6 \mathrm{~Hz}$ fully kindled mice. (d) Number of partial and generalized seizures following vehicle $(0.9 \% \mathrm{NaCl})$ and $50 \mathrm{mg} / \mathrm{kg}$ TG19 i.p treatment in fully kindled mice. Statistics: (b and c) Two-sided Wilcoxon matched-pairs signedrank with ${ }^{*} p<.05$, (d) Two-sided Fisher's exact test with ${ }^{* *} p<.01$

decreased seizure scores or seizure duration. Mechanistically, pilocarpine acted as a trigger of HC opening (based on dye uptake assays) in acute hippocampal brain slices, which was also inhibited by TATGap19. Moreover, in vivo microdialysis-delivered pilocarpine increased D-serine levels in the extracellular fluid, which was suppressed by TATGap19. Taken overall, these results indicate that $\mathrm{C} x 43 \mathrm{HC}$ inhibition impacts seizure activity and that $\mathrm{C} \times 43 \mathrm{HC}$ opening promotes seizure activity. Below we discuss these findings in more detail.

The chemoconvulsant pilocarpine induced $\mathrm{EtBr}$ uptake in astrocytes that was approximately twice as large compared with control conditions. $\mathrm{EtBr}$ is a fluorescent tracer that passes from the extracellular environment to nuclei of cells through either disrupted plasma membranes or membrane channels that allow $\mathrm{EtBr}$ to pass through, such as $\mathrm{Cx}$ HCs. The uptake is proportional to the number of active (open) HCs (Johnson et al., 2016). We found that both CBX and TAT-Gap19 significantly decreased pilocarpine-induced EtBr uptake in GFAP-positive astrocytes. CBX has a larger spectrum of effects, which includes inhibition of Cx-based GJCs and HCs (e.g., astrocytic Cx30 (Hansen et al., 2014; Pannasch et al., 2014) and neuronal Cx36 (Allison et al., 2011) as well as pannexin-based channels (Bruzzone, Barbe,
Jakob, \& Monyer, 2005). Moreover, CBX has several other well-known off-target effects, including the inhibition of voltage-gated $\mathrm{Ca}^{2+}$ currents and synaptic transmission, as well as effects on gammaaminobutyric acid (GABA) receptors that all largely affect electrical excitability (Connors 2012; Vessey et al., 2004). None of the control peptides affected $\mathrm{EtBr}$ uptake in pilocarpine treated slices, so effects of TAT-Gap19 resulted from Cx43 HC inhibition as this peptide was demonstrated not to affect pannexin1 channels (Wang et al., 2013ba). Of note, we used GFAP-eGFP expressing transgenic mice as a tool to visualize astrocytes. In these mice, not all astrocytes are GFAP-positive and we also observed EtBr uptake in GFAP-negative cells, which may represent neurons, GFAP-negative astrocytes (Houades et al., 2006) or microglial cells as reported by others (Abudara et al., 2014). As pilocarpine acts on neurons, it is conceivable that most of these cells are neurons, especially since TAT-Gap19 did not diminish the EtBr uptake and adult neurons do not express Cx43 (Theis et al., 2003). Here, we only quantified EtBr uptake in GFAP-positive cells and uptake was significantly inhibited by TAT-Gap19, indicating involvement of astroglial Cx43 HCs. The pilocarpine-induced $\mathrm{C} \times 43 \mathrm{HC}$ opening can be initiated via various mechanisms. Pilocarpine induces seizures via its agonistic 
effect on neuronal muscarinic M1 receptors and triggers epileptiform activity in hippocampal slices (Portelli et al., 2012). As such, pilocarpine strongly promotes electrical excitability, leading to an elevation of $\left[\mathrm{K}^{+}\right]_{\mathrm{e}}$ and a lowering of $\left[\mathrm{Na}^{+}\right]_{\mathrm{e}}$ and $\left[\mathrm{Ca}^{2+}\right]_{\mathrm{e}}$ (Somjen, 2002). $\left[\mathrm{Ca}^{2+}\right]_{\mathrm{e}}$ can drop by $0.6-1.15 \mathrm{mM}$ below the normal physiological level as reported in various epilepsy models (Heinemann, Konnerth, Pumain, \& Wadman, 1986). Alterations in this range have been demonstrated to trigger Cx43 HC opening based on various approaches including pore size changes, electrophysiology and ATP release (Bruzzone, Guida, Zocchi, Franco, \& De Flora, 2001; Contreras, Sáez, Bukauskas, \& Bennett, 2003; De Vuyst et al., 2009; Lopez et al., 2016; Thimm, Mechler, Lin, Rhee, \& Lal, 2005; Torres et al., 2012; Ye et al., 2003). M1 receptors are also expressed on astrocytes (Shelton \& McCarthy, 2000) so pilocarpine may well be directly targeting astrocytes, thereby signaling through $\mathrm{G}_{\mathrm{q}}$-proteins that activate phospholipase $\mathrm{C}$, produce inositol trisphosphate and lead to an elevation of the astrocytic $\left[\mathrm{Ca}^{2+}\right]_{i}$. Recent evidence indicates that $\left[\mathrm{Ca}^{2+}\right]_{i}$ elevation, besides its modulatory effect on voltage-triggered HC opening (Wang et al., 2012), may also directly trigger $\mathrm{HC}$ opening in voltage clamped astrocytes at $-70 \mathrm{mV}$ (Meunier et al., 2017; reviewed in Leybaert et al., 2017). Astrocytic [Ca $\left.{ }^{2+}\right]_{i}$ elevation is a common theme in various epilepsy models (Carmignoto \& Haydon, 2012), making it a likely trigger for epileptic Cx43 HC opening. Additionally, since pilocarpine was acutely added to the slices, we demonstrated the involvement of astrocytic Cx43 HCs in epileptiform activity. Opening of astrocytic Cx43 HCs may contribute to the seizurogenic effect of pilocarpine by loss of essential cellular metabolites, by disturbed transmembrane ion fluxes (De Bock et al., 2014; Giaume et al., 2013; Montero \& Orellana, 2015; Wei et al., 2014), by possibly leading to cell swelling, by provoking cell death (Decrock et al., 2009) and/or by releasing (excitatory) gliotransmitters (e.g., glutamate, D-serine; Orellana et al., 2011; Stehberg et al., 2012). Glutamate is the major excitatory transmitter in the brain and elevated levels have been reported in human brain tissues of patients with epilepsy and animal models of epilepsy. Elevated extracellular glutamate concentrations can induce N-methyl-D-aspartate (NMDA) receptor-mediated excitotoxicity, which causes neuronal death in epilepsy (Cho, 2013). Besides glutamate, astrocyte-released D-serine acts as an important modulator of NMDA receptors, thereby promoting their opening, increasing excitability and seizure generation (Clasadonte \& Haydon, 2012).

The detailed mechanism underlying astrocytic D-serine release is still unknown but is in general assumed to be dependent on an increase in cytosolic $\mathrm{Ca}^{2+}$. Astrocytic D-serine release has been reported to occur via large vesicles and $\mathrm{Ca}^{2+}$-dependent exocytosis (Orellana \& Stehberg, 2014). Moreover, a recent study performed in prefrontal cortex slices has shown that in basal conditions, D-serine released by astrocytes is associated to $\mathrm{C} \times 43 \mathrm{HC}$ activity and is triggered by increases in $\left[\mathrm{Ca}^{2+}\right]_{i}$ in astrocytes voltage clamped at $-70 \mathrm{mV}$ (Meunier et al., 2017). Up to now, only one in vivo study proposed that astrocytic Cx43 HCs might release D-serine (Stehberg et al., 2012). In this paper, Stehberg and colleagues investigated the effect of $\mathrm{Cx} 43 \mathrm{HC}$ inhibition in a fear-based memory paradigm by using another $\mathrm{Cx} 43 \mathrm{HC}$ inhibitor called TAT-L2. Of note, the L2 peptide is composed of a sequence which comprises the Gap19 sequence used in the present study; in fact, the Gap19 sequence is the most active part within the L2 sequence (Wang et al., 2013a). TAT-L2 impaired fear memory consolidation in the basolateral amygdala and the effect was reversed by administering a cocktail of gliotransmitters (glutamate, glutamine, lactate, D-serine, glycine, and ATP). The authors therefore postulated that gliotransmitter release from astrocytes occurred through $\mathrm{C} \times 43 \mathrm{HCs}$. Although this study nicely supports the hypothesis that $\mathrm{Cx} 43 \mathrm{HCs}$ contribute to gliotransmission, the exact gliotransmitters released were not identified nor measured.

We here show for the first time that seizure-enhanced $D$-serine dialysate levels can be diminished by TAT-Gap19, suggesting that astrocytic $\mathrm{Cx} 43 \mathrm{HCs}$ contribute to D-serine release in vivo. This hypothesis was further strengthened as the anticonvulsant action of TATGap19 was abolished by exogenous D-serine co-administration. D-serine was administered acutely at a high dose since it causes fairly robust behavioral effects and significant increases in brain and extracellular Dserine content, in contrast to inhibitors of $\mathrm{D}$-amino acid oxidase (DAAO; i.e., the enzyme that degrades D-serine; Smith, Uslaner, \& Hutson, 2010). Although for future chronic experiments, co-administration of D-serine with a DAAO inhibitor might reduce the dose of $D$-serine and ameliorate side effects associated with high doses of chronic D-serine administration, such as nephrotoxicity (Chung et al., 2010; Maekawa et al., 2005; Park et al., 2006; Rojas et al., 2016). Our data suggest that TAT-Gap19 protects against seizures by blocking Cx43 HC-mediated D-serine release. However, the results do not necessarily mean that D-serine is released directly through $\mathrm{Cx} 43 \mathrm{HCs}$. Indeed, open HCs can facilitate $\mathrm{Ca}^{2+}$ entry (Bol et al., 2017; Schalper et al., 2010) that in turn could trigger $\mathrm{Ca}^{2+}$-dependent exocytosis or alternative $\mathrm{Ca}^{2+}$-dependent release mechanisms of D-serine indirectly (Hamilton \& Attwell, 2010; Martineau, Parpura, \& Mothet, 2014).

A possible model-dependent anticonvulsant action of TAT-Gap19 was excluded as TAT-Gap19 retained its effect in an electricallyinduced refractory seizure model and a clinically relevant kindling model of epilepsy displaying treatment-resistant seizures. Of note, in 2015 the ETSP of NINDS was revised to include preclinical approaches to model pharmacoresistant seizures. Therefore, the acute $6 \mathrm{~Hz}$ electrical stimulation ( $>44 \mathrm{~mA}$ ) model and etiologically-relevant chronic disease models, such as corneal kindling models, are now also incorporated in the initial "Identification" phase of active compounds (Barker-Haliski et al., 2017).

The anticonvulsant effects of $\mathrm{Cx} 43 \mathrm{HC}$ inhibition against refractory seizures we report in this article underscores again the important role of glia in epilepsy and supports the proceeding of TAT-Gap19 to the late ("Differentiation") phase (i.e., phase with more resource-intensive tests) of the ETSP. Peptidomimetics, neuropeptides and peptidergic targets are indeed one of the research priorities for the development of new ASDs with original mechanisms of action. Since peptides often have low bioavailability (e.g., limited blood-brain barrier penetration; Dobolyi et al., 2014), TAT-Gap19 was administered in several of our experiments directly into the brain to demonstrate its anticonvulsive properties. Regardless, TAT-Gap19 was also CNS-active after systemic administration, indicating favorable blood-brain permeability properties and the possible application as a drug. Different TAT- 
Gap19 doses were required depending on the used model (i.e., distinct seizure induction, administration routes, species and seizure severity assessments).

In conclusion, our study is the first to demonstrate that attenuation of D-serine dialysate levels is crucial for the anticonvulsant properties of TAT-Gap19. We propose Cx43 HCs as a novel and druggable target against seizures, encouraging the further assessment of $\mathrm{C} x 43 \mathrm{HC}$ blockers in additional chronic models of epilepsy.

\section{ACKNOWLEDGMENT}

This study was financially supported by the Vrije Universiteit Brussel (VUB) (OZR2102), the European Research Council (ERC Starting Grant 335476) and the Fund for scientific Research Flanders (FWO Vlaanderen) (Grant nrs. G.0298.11, G.0571.12, G.0A54.13 and G.0320.15). Research in the Leybaert group is supported by the FWO Vlaanderen (grant G.0A82.13N), the Interuniversity Attraction Poles Program (grant P7/10), Ghent University (Special Research Fund (BOF)) and the Geneeskundige Stichting Koningin Elisabeth (grant STI.DI2.2017.0004.01). We thank Carina De Rijck and Ria Berckmans (VUB) for their technical assistance with HPLC analyses, Gino De Smet (VUB) for surgery training, Pascal Ezan, Chenju Yi and Annette Koulakoff (CIRB, Collège de France) for dye uptake training, Jérémie Teillon (CIRB, Collège de France) for confocal image analysis training and Philippe Mailly (CIRB, Collège de France) for developing macro's for analyses with Fiji software.

\section{CONFLICT OF INTEREST STATEMENT}

None of the authors have any conflict of interest to disclose.

\section{ORCID}

Laura Walrave (D) http://orcid.org/0000-0002-7973-7595

Ann Van Eeckhaut (DD http://orcid.org/0000-0002-1695-7398

\section{REFERENCES}

Abudara, V., Bechberger, J., Freitas-Andrade, M., De Bock, M., Wang, N., Bultynck, G., ... Giaume, C. (2014). The connexin43 mimetic peptide Gap19 inhibits hemichannels without altering gap junctional communication in astrocytes. Frontiers in Cellular Neuroscience, 8, 306. https://doi.org/10.3389/fncel.2014.00306

Abudara, V., Roux, L., Dallérac, G., Matias, I., Dulong, J., Mothet, J. P., ... Giaume, C. (2015). Activated microglia impairs neuroglial interaction by opening $\mathrm{C} \times 43$ hemichannels in hippocampal astrocytes. Glia, 63(5), 795-811. https://doi.org/10.1002/glia.22785.

Allison, D. W., Wilcox, R. S., Ellefsen, K. L., Askew, C. E., Hansen, D. M., Wilcox, J. D., ... Steffensen, S. C. (2011). Mefloquine effects on ventral tegmental area dopamine and GABA neuron inhibition: A physiologic role for connexin-36 gap junctions. Synapse, 65(8), 804-813. https://doi.org/10.1002/syn.20907.

Barker-Haliski, M. L., Johnson, K., Billingsley, P., Huff, J., Handy, L. J., Khaleel, R., ... Wilcox, K. S. (2017). Validation of a preclinical drug screening platform for pharmacoresistant epilepsy. Neurochemical Research, 42(7), 1904-1918. https://doi.org/10.1007/s11064-0172227-7.
Barton, M. E., Klein, B. D., Wolf, H. H., \& White, H. S. (2001). Pharmacological characterization of the $6 \mathrm{~Hz}$ psychomotor seizure model of partial epilepsy. Epilepsy Research, 47(3), 217-227. https://doi.org/10. 1016/S0920-1211(01)00302-3.

Baulac, M., \& Pitkänen, A. (2008). Research priorities in epilepsy for the next decade - A representative view of the European Scientific Community. Epilepsia. Epub 2008/09/25. https://doi.org/10.1111/j.15281167.2008.01811.x.

Bol, M., Wang, N., De Bock, M., Wacquier, B., Decrock, E., Gadicherla, A., ... Leybaert, L. (2017). At the cross-point of connexins, calcium, and ATP: Blocking hemichannels inhibits vasoconstriction of rat small mesenteric arteries. Cardiovascular Research, 113(2), 195-206. https://doi.org/10.1093/cvr/cvw215.

Bruzzone, R., Barbe, M. T., Jakob, N. J., \& Monyer, H. (2005). Pharmacological properties of homomeric and heteromeric pannexin hemichannels expressed in Xenopus oocytes. Journal of Neurochemistry, 92(5), 1033-1043. https://doi.org/10.1111/j.1471-4159.2004.02947.x.

Bruzzone, S., Guida, L., Zocchi, E., Franco, L., \& De Flora, A. (2001). Connexin 43 hemichannels mediate $\mathrm{Ca} 2+$-regulated transmembrane NAD + fluxes in intact cells. FASEB Journal, 15(1), 10-12. https://doi. org/10.1096/fj.00-0566fje.

Carlen, P. L. (2012). Curious and contradictory roles of glial connexins and pannexins in epilepsy. Brain Research, 1487, 54-60. https://doi. org/10.1016/j.brainres.2012.06.059.

Carmignoto, G., \& Haydon, P. G. (2012). Astrocyte calcium signaling and epilepsy. Glia, 60(8), 1227-1233. https://doi.org/10.1002/glia.22318.

Chever, O., Lee, C. Y., \& Rouach, N. (2014). Astroglial connexin43 hemichannels tune basal excitatory synaptic transmission. The Journal of Neuroscience: The Official Journal of the Society for Neuroscience, 34 (34), 11228-11232. https://doi.org/10.1523/JNEUROSCI.0015-14. 2014.

Chever, O., Pannasch, U., Ezan, P., \& Rouach, N. (2014). Astroglial connexin 43 sustains glutamatergic synaptic efficacy. Philosophical Transactions of the Royal Society of London Series B, Biological Sciences, 369 (1654), 20130596. https://doi.org/10.1098/rstb.2013.0596.

Cho, C. H. (2013). New mechanism for glutamate hypothesis in epilepsy. Frontiers in Cellular Neuroscience, 7, 127. https://doi.org/10.3389/ fncel.2013.00127.

Chung, S. P., Sogabe, K., Park, H. K., Song, Y., Ono, K., Abou El-Magd, R. M., ... Fukui, K. (2010). Potential cytotoxic effect of hydroxypyruvate produced from $\mathrm{D}$-serine by astroglial $\mathrm{D}$-amino acid oxidase. Journal of Biochemistry, 148(6), 743-753. https://doi.org/10.1093/jb/mvq112.

Clasadonte, J., \& Haydon, P. G. (2012). Jasper's basic mechanisms of the epilepsies, chapter astrocytes and epilepsy. (4th ed.). Bethesda, MD: National Center for Biotechnology Information (US).

Connors, B. W. (2012). Tales of a dirty drug: Carbenoxolone, gap junctions, and seizures. Epilepsy Currents, 12(2), 66-68. https://doi.org/ 10.5698/1535-7511-12.2.66.

Contreras, J. E., Sáez, J. C., Bukauskas, F. F., \& Bennett, M. V. (2003). Gating and regulation of connexin43 (Cx43) hemichannels. Proceedings of the National Academy of Sciences of the United States of America, 100 (20), 11388-11393. https://doi.org/10.1073/pnas.1434298100.

Coppens, J., Aourz, N., Walrave, L., Fehrentz, J. A., Martinez, J., De Bundel, D., ... Smolders, I. J. (2016). Anticonvulsant effect of a ghrelin receptor agonist in $6 \mathrm{~Hz}$ corneally kindled mice. Epilepsia, 57(9), E195-E199. https://doi.org/10.1111/epi.13463.

Curia, G., Longo, D., Biagini, G., Jones, R. S., \& Avoli, M. (2008). The pilocarpine model of temporal lobe epilepsy. Journal of Neuroscience Methods, 172(2), 143-157. https://doi.org/10.1016/j.jneumeth.2008. 04.019 . 
De Bock, M., Decrock, E., Wang, N., Bol, M., Vinken, M., Bultynck, G., \& Leybaert, L. (2014). The dual face of connexin-based astroglial Ca $(2+)$ communication: A key player in brain physiology and a prime target in pathology. Biochimica Et Biophysica Acta, 1843(10), 22112232. https://doi.org/10.1016/j.bbamcr.2014.04.016.

De Vuyst, E., Wang, N., Decrock, E., De Bock, M., Vinken, M., Van Moorhem, M., ... Leybaert, L. (2009). $\mathrm{Ca}(2+)$ regulation of connexin 43 hemichannels in C6 glioma and glial cells. Cell Calcium, 46(3), 176187. https://doi.org/10.1016/j.ceca.2009.07.002.

Decrock, E., De Vuyst, E., Vinken, M., Van Moorhem, M., Vranckx, K., Wang, N., ... Leybaert, L. (2009). Connexin 43 hemichannels contribute to the propagation of apoptotic cell death in a rat C6 glioma cell model. Cell Death \& Differentiation, 16(1), 151-163. https://doi.org/ 10.1038/cdd.2008.138.

Dobolyi, A., Kekesi, K. A., Juhasz, G., Székely, A. D., Lovas, G., \& Kovács, Z. (2014). Receptors of peptides as therapeutic targets in epilepsy research. Current Medicinal Chemistry, 21(6), 764-787. https://doi. org/10.2174/0929867320666131119154018.

Duffy, S., Labrie, V., \& Roder, J. C. (2008). D-serine augments NMDANR2B receptor-dependent hippocampal long-term depression and spatial reversal learning. Neuropsychopharmacology, 33(5), 10041018. https://doi.org/10.1038/sj.npp.1301486.

European Community Council Directives 2010/63/EU of the European Parliament and the Council on the protection of animals used for scientific purposes; Official Journal of the European Union, L 276, 20 October 2010. https://doi.org/10.3000/17252555.L_2010.276.eng.

Giaume, C., Leybaert, L., Naus, C. C., \& Sáez, J. C. (2013). Connexin and pannexin hemichannels in brain glial cells: Properties, pharmacology, and roles. Frontiers in Pharmacology, 4, 88. https://doi.org/10.3389/ fphar.2013.00088.

Giaume, C., Orellana, J. A., Abudara, V., \& Sáez, J. C. (2012). Connexinbased channels in astrocytes: How to study their properties. Methods in Molecular Biology, 814, 283-303. https://doi.org/10.1007/978-161779-452-0_19.

Giaume, C., \& Theis, M. (2010). Pharmacological and genetic approaches to study connexin-mediated channels in glial cells of the central nervous system. Brain Research Reviews, 63(1-2), 160-176. https://doi. org/10.1016/j.brainresrev.2009.11.005.

Gómez-Galán, M., De Bundel, D., Van Eeckhaut, A., Smolders, I. J., \& Lindskog, M. (2013). Dysfunctional astrocytic regulation of glutamate transmission in a rat model of depression. Molecular Psychiatry, 18(5), 582-594. https://doi.org/10.1038/mp.2012.10.

Hamilton, N. B., \& Attwell, D. (2010). Do astrocytes really exocytose neurotransmitters? Nature Reviews Neuroscience, 11(4), 227-238. https://doi.org/10.1038/nrn2803.

Hansen, D. B., Ye, Z. C., Calloe, K., Braunstein, T. H., Hofgaard, J. P., Ransom, B. R., ... MacAulay, N. (2014). Activation, permeability, and inhibition of astrocytic and neuronal large pore (hemi)channels. Journal of Biological Chemistry, 289(38), 26058-26073. https://doi.org/ 10.1074/jbc.M114.582155.

Heinemann, U., Konnerth, A., Pumain, R., \& Wadman, W. J. (1986). Extracellular calcium and potassium concentration changes in chronic epileptic brain tissue. Advances in Neurology, 44, 641-661.

Hervé, J. C., \& Sarrouilhe, D. (2005). Connexin-made channels as pharmacological targets. Current Pharmaceutical Design, 11(15), 19411958. https://doi.org/10.2174/1381612054021060.

Houades, V., Rouach, N., Ezan, P., Kirchhoff, F., Koulakoff, A., \& Giaume, C. (2006). Shapes of astrocyte networks in the juvenile brain. Neuron Glia Biology, 2(01), 3-14. https://doi.org/10.1017/S1740925X06000081.

lyyathurai, J., D'Hondt, C., Wang, N., De Bock, M., Himpens, B., Retamal, M. A., ... Bultynck, G. (2013). Peptides and peptide-derived molecules targeting the intracellular domains of Cx43: Gap junctions versus hemichannels. Neuropharmacology, 75, 491-505. https://doi. org/10.1016/j.neuropharm.2013.04.050.

Janigro, D., \& Walker, M. C. (2014). What non-neuronal mechanisms should be studied to understand epileptic seizures? Advances in Experimental Medicine and Biology, 813, 253-264. https://doi.org/10. 1007/978-94-017-8914-1_20.

Jin, M. M., \& Chen, Z. (2011). Role of gap junctions in epilepsy. Neuroscience Bulletin, 27(6), 389-406. https://doi.org/10.1007/s12264011-1944-1.

Johnson, R. G., Le, H. C., Evenson, K., Loberg, S. W., Myslajek, T. M., Prabhu, A., ... Sheridan, J. D. (2016). Connexin hemichannels: Methods for dye uptake and leakage. The Journal of Membrane Biology, 249(6), 713-741. https://doi.org/10.1007/s00232-016-9925-y.

Kang, J., Kang, N., Lovatt, D., Torres, A., Zhao, Z., Lin, J., \& Nedergaard, M. (2008). Cx43 hemichannels are permeable to ATP. Journal of Neuroscience, 28(18), 4702-4711. https://doi.org/10.1523/JNEUROSCI. 5048-07.2008.

Kilkenny, C., Browne, W. J., Cuthill, I. C., Emerson, M., \& Altman, D. G. (2010). Improving bioscience research reporting: The ARRIVE guidelines for reporting animal research. PLoS Biology, 8(6), e1000412. https://doi.org/10.1371/journal.pbio.1000412.

Kwan, P., Schachter, S. C., \& Brodie, M. J. (2011). Drug-resistant epilepsy. New England Journal of Medicine, 365(10), 919-926. https:// doi.org/10.1056/NEJMra1004418.

Leclercq, K., Matagne, A., \& Kaminski, R. M. (2014). Low potency and limited efficacy of antiepileptic drugs in the mouse $6 \mathrm{~Hz}$ corneal kindling model. Epilepsy Research, 108(4), 675-683. https://doi.org/10. 1016/j.eplepsyres.2014.02.013.

Leybaert, L., Lampe, P. D., Dhein, S., Kwak, B. R., Ferdinandy, P., Beyer, E. C., ... Schulz, R. (2017). Connexins in cardiovascular and neurovascular health and disease: Pharmacological implications. Pharmacological Reviews, 69(4), 396-478. https://doi.org/10.1124/pr.115.012062.

Li, X., Zhao, H., Tan, X., Kostrzewa, R. M., Du, G., Chen, Y., ... Xu, X. (2015). Inhibition of connexin43 improves functional recovery after ischemic brain injury in neonatal rats. Glia, 63(9), 1553-1567. https://doi.org/10.1002/glia.22826.

Lohman, A. W., \& Isakson, B. E. (2014). Differentiating connexin hemichannels and pannexin channels in cellular ATP release. FEBS Letters, 588(8), 1379-1388. https://doi.org/10.1016/j.febslet.2014.02.004.

Lopez, W., Ramachandran, J., Alsamarah, A., Luo, Y., Harris, A. L., \& Contreras, J. E. (2016). Mechanism of gating by calcium in connexin hemichannels. Proceedings of the National Academy of Sciences, 113(49), E7986-E7995. https://doi.org/10.1073/pnas.1609378113.

Maekawa, M., Okamura, T., Kasai, N., Hori, Y., Summer, K. H., \& Konno, R. (2005). D-amino-acid oxidase is involved in D-serine-induced nephrotoxicity. Chemical Research in Toxicology, 18(11), 1678-1682. https://doi.org/10.1021/tx0500326.

Marchi, N., Oby, E., Batra, A., Uva, L., De Curtis, M., Hernandez, N., .. Janigro, D. (2007). In vivo and in vitro effects of pilocarpine: Relevance to ictogenesis. Epilepsia, 48(10), 1934-1946. doi 10.1111/ j.1528-1167.2007.01185.x.

Martineau, M., Parpura, V., \& Mothet, J. P. (2014). Cell-type specific mechanisms of D-serine uptake and release in the brain. Frontiers in Synaptic Neuroscience, 6, 12. https://doi.org/10.3389/fnsyn.2014. 00012. https://doi.org/10.3389/fnsyn.2014.00012.

Meunier, C., Wang, N., Yi, C., Dallérac, G., Ezan, P., Koulakoff, A., .. Giaume, C. (2017). Contribution of astroglial Cx43 hemichannels to the modulation of glutamatergic currents by $\mathrm{D}$-serine in the mouse prefrontal cortex. Journal of Neuroscience, 2204-16.2017. https://doi. org/10.1523/JNEUROSCI.2204-16.2017. 
Meurs, A., Clinckers, R., Ebinger, G., Michotte, Y., \& Smolders, I. J. (2008). Seizure activity and changes in hippocampal extracellular glutamate, GABA, dopamine and serotonin. Epilepsy Research, 78(1), 5059. https://doi.org/10.1016/j.eplepsyres.2007.10.007

Montero, T. D., \& Orellana, J. A. (2015). Hemichannels: New pathways for gliotransmitter release. Neuroscience, 286, 45-59. https://doi.org/ 10.1016/j.neuroscience.2014.11.048.

Mylvaganam, S., Ramani, M., Krawczyk, M., \& Carlen, P. L. (2014). Roles of gap junctions, connexins, and pannexins in epilepsy. Frontiers in Physiology, 5, 172. https://doi.org/10.3389/fphys.2014.00172. https://doi.org/10.3389/fphys.2014.00172.

Mylvaganam, S., Zhang, L., Wu, C., Zhang, Z. I., Samoilova, M., Eubanks, J., ... Poulter, M. O. (2010). Hippocampal seizures alter the expression of the pannexin and connexin transcriptome. Journal of Neurochemistry, 112(1), 92-102. https://doi.org/10.1111/j.1471-4159. 2009.06431.x.

Nagao, T., Alonso, A., \& Avoli, M. (1996). Epileptiform activity induced by pilocarpine in the rat hippocampal-entorhinal slice preparation. Neuroscience, 72(2), 399-408. https://doi.org/10.1016/0306-4522 (95)00534-X.

Nagy, J. I., \& Rash, J. E. (2000). Connexins and gap junctions of astrocytes and oligodendrocytes in the CNS. Brain Research Reviews, 32(1), 29-44. https://doi.org/10.1016/S0165-0173(99)00066-1.

Naus, C. C., Bechberger, J. F., Caveney, S., \& Wilson, J. X. (1991). Expression of Gap Junction Genes in Astrocytes and C6 Glioma-Cells. Neuroscience Letters, 126(1), 33-36. https://doi.org/10.1016/0304-3940 (91)90364-Y.

Nielsen, B. S., Hansen, D. B., Ransom, B. R., Nielsen, M. S., \& MacAulay, N. (2017). Connexin hemichannels in astrocytes: An assessment of controversies regarding their functional characteristics. Neurochemical Research, 42(9), 2537-2550. https://doi.org/10.1007/s11064-0172243-7.

Nolte, C., Matyash, M., Pivneva, T., Schipke, C. G., Ohlemeyer, C., Hanisch, U. K., ... Kettenmann, H. (2001). GFAP promoter-controlled EGFP-expressing transgenic mice: A tool to visualize astrocytes and astrogliosis in living brain tissue. Glia, 33(1), 72-86. https://doi. org/10.1002/1098-1136(20010101)33:1<72::AID-GLIA1007>3. $0 . \mathrm{CO} ; 2-\mathrm{A}$.

Omasits, U., Ahrens, C. H., Müller, S., \& Wollscheid, B. (2014). Protter: Interactive protein feature visualization and integration with experimental proteomic data. Bioinformatics, 30(6), 884-886. https://doi. org/10.1093/bioinformatics/btt607.

Orellana, J. A., Froger, N., Ezan, P., Jiang, J. X., Bennett, M. V., Naus, C. C., ... Sáez, J. C. (2011). ATP and glutamate released via astroglial connexin 43 hemichannels mediate neuronal death through activation of pannexin 1 hemichannels. Journal of Neurochemistry, 118(5), 826840. https://doi.org/10.1111/j.1471-4159.2011.07210.x.

Orellana, J. A., Retamal, M. A., Moraga-Amaro, R., \& Stehberg, J. (2016). Role of astroglial hemichannels and pannexons in memory and neurodegenerative diseases. Frontiers in Integrative Neuroscience, https:// doi.org/10.3389/fnint.2016.00026.

Orellana, J. A., \& Stehberg, J. (2014). Hemichannels: New roles in astroglial function. Frontiers in Physiology, 5, 193. https://doi.org/10.3389/ fphys.2014.00193.

Pannasch, U., Freche, D., Dallérac, G., Ghézali, G., Escartin, C., Ezan, P., ... Rouach, N. (2014). Connexin 30 sets synaptic strength by controlling astroglial synapse invasion. Nature Neuroscience, 17(4), 549-558. https://doi.org/10.1038/nn.3662.

Pannasch, U., \& Rouach, N. (2013). Emerging role for astroglial networks in information processing: From synapse to behavior. Trends in Neurosciences, 36(7), 405-417. https://doi.org/10.1016/j.tins.2013.04.004.
Park, H. K., Shishido, Y., Ichise-Shishido, S., Kawazoe, T., Ono, K., Iwana, S., ... Fukui, K. (2006). Potential role for astroglial D-amino acid oxidase in extracellular D-serine metabolism and cytotoxicity. The Journal of Biochemistry, 139(2), 295-304. https://doi.org/10.1093/jb/mvj036.

Paxinos, G., \& Franklin, K. B. (2004). The mouse brain in stereotaxic coordinates (Compact 2nd ed.). San Diego, CA: Elsevier Academic Press.

Paxinos, G., \& Watson, C. (2005). The rat brain in stereotaxic coordinates (5th ed.). Amsterdam; Boston: Elsevier Academic Press.

Portelli, J., Thielemans, L., Ver Donck, L., Loyens, E., Coppens, J., Aourz, N., ... Smolders, I. J. (2012). Inactivation of the constitutively active ghrelin receptor attenuates limbic seizure activity in rodents. Neurotherapeutics, 9(3), 658-672. https://doi.org/10.1007/s13311-012-0125-x.

Racine, R. J. (1972). Modification of seizure activity by electrical stimulation. II. Motor seizure. Electroencephalography and Clinical Neurophysiology, 32(3), 281-294. https://doi.org/10.1016/0013-4694(72)90177-0.

Rais, R., Thomas, A. G., Wozniak, K., Wu, Y., Jaaro-Peled, H., Sawa, A., ... Tsukamoto, T. (2012). Pharmacokinetics of oral D-serine in Damino acid oxidase knockout mice. Drug Metabolism and Disposition: The Biological Fate of Chemicals, 40(11), 2067-2073. https://doi.org/ 10.1124/dmd.112.046482.

Rojas, C., Alt, J., Ator, N. A., Thomas, A. G., Wu, Y., Hin, N., ... Slusher, B. S. (2016). D-amino-acid oxidase inhibition increases d-serine plasma levels in mouse but not in monkey or dog. Neuropsychopharmacology, 41(6), 1610-1619. https://doi.org/10.1038/npp.2015.319.

Schalper, K. A., Sanchez, H. A., Lee, S. C., Altenberg, G. A., Nathanson, M. H., \& Sáez, J. C. (2010). Connexin 43 hemichannels mediate the $\mathrm{Ca} 2+$ influx induced by extracellular alkalinization. American Journal of Physiology Cell Physiology, 299(6), C1504-C1515. https://doi.org/ 10.1152/ajpcell.00015.2010.

Schindelin, J., Arganda-Carreras, I., Frise, E., Kaynig, V., Longair, M., Pietzsch, T., ... Cardona, A. (2012). Fiji: An open-source platform for biological-image analysis. Nature Methods, 9(7), 676-682. https://doi. org/10.1038/nmeth.2019.

Seif, T., Simms, J. A., Lei, K., Wegner, S., Bonci, A., Messing, R. O., \& Hopf, F. W. (2015). D-serine and D-cycloserine reduce compulsive alcohol intake in rats. Neuropsychopharmacology, 40(10), 2357-2367. https://doi.org/10.1038/npp.2015.84.

Shelton, M. K., \& McCarthy, K. D. (2000). Hippocampal astrocytes exhibit $\mathrm{Ca}^{2+}$-elevating muscarinic cholinergic and histaminergic receptors in situ. Journal of Neurochemistry, 74(2), 555-563. https://doi.org/10. 1046/j.1471-4159.2000.740555.x

Smith, S. M., Uslaner, J. M., \& Hutson, P. H. (2010). The therapeutic potential of D-amino acid oxidase (DAAO) inhibitors. The Open Medicinal Chemistry Journal, 4, 3-9. https://doi.org/10.2174/ 1874104501004020003.

Somjen, G. G. (2002). Ion regulation in the brain: Implications for pathophysiology. The Neuroscientist, 8(3), 254-267. https://doi.org/10. 1177/1073858402008003011.

Stehberg, J., Moraga-Amaro, R., Salazar, C., Becerra, A., Echeverría, C., Orellana, J. A., ... Retamal, M. A. (2012). Release of gliotransmitters through astroglial connexin 43 hemichannels is necessary for fear memory consolidation in the basolateral amygdala. FASEB Journal, 26 (9), 3649-3657. https://doi.org/10.1096/fj.11-198416.

Suadicani, S. O., De Pina-Benabou, M. H., Urban-Maldonado, M., Spray, D. C., \& Scemes, E. (2003). Acute downregulation of Cx43 alters P2Y receptor expression levels in mouse spinal cord astrocytes. Glia, 42 (2), 160-171. https://doi.org/10.1002/glia.10197.

Theis, M., Jauch, R., Zhuo, L., Speidel, D., Wallraff, A., Döring, B., ... Willecke, K. (2003). Accelerated hippocampal spreading depression and enhanced locomotory activity in mice with astrocyte-directed inactivation of connexin43. Journal of Neuroscience, 23(3), 766-776. 
Thimm, J., Mechler, A., Lin, H., Rhee, S., \& Lal, R. (2005). Calciumdependent open/closed conformations and interfacial energy maps of reconstituted hemichannels. Journal of Biological Chemistry, 280(11), 10646-10654. https://doi.org/10.1074/jbc.M412749200.

Torres, A., Wang, F., Xu, Q., Fujita, T., Dobrowolski, R., Willecke, K., ... Nedergaard, M. (2012). Extracellular $\mathrm{Ca}(2)(+)$ acts as a mediator of communication from neurons to glia. Science Signaling, 5(208), ra8. https://doi.org/10.1126/scisignal.2002160.

Vessey, J. P., Lalonde, M. R., Mizan, H. A., Welch, N. C., Kelly, M. E., \& Barnes, S. (2004). Carbenoxolone inhibition of voltage-gated Ca channels and synaptic transmission in the retina. Journal of Neurophysiology, 92(2), 1252-1256. https://doi.org/10.1152/jn.00148.2004.

Vinken, M. (2015). Connexin hemichannels: Novel mediators of toxicity. Archives of Toxicology, 89(1), 143-145. https://doi.org/10.1007/ s00204-014-1422-4.

Walrave, L., Maes, K., Coppens, J., Bentea, E., Van Eeckhaut, A., Massie, A., ... Smolders, I. J. (2015). Validation of the $6 \mathrm{~Hz}$ refractory seizure mouse model for intracerebroventricularly administered compounds. Epilepsy Research, 115, 67-72. https://doi.org/10.1016/j.eplepsyres.2015.06.003.

Walrave, L., Vinken, M., Albertini, G., De Bundel, D., Leybaert, L., \& Smolders, I. J. (2016). Inhibition of connexin43 hemichannels impairs spatial shortterm memory without affecting spatial working memory. Frontiers in Cellular Neuroscience, 10, 288. https://doi.org/10.3389/fncel.2016.00288.

Wang, N., De Bock, M., Antoons, G., Gadicherla, A. K., Bol, M., Decrock, E., ... Leybaert, L. (2012). Connexin mimetic peptides inhibit Cx43 hemichannel opening triggered by voltage and intracellular $\mathrm{Ca} 2+$ elevation. Basic Research in Cardiology, 107(6), 304. https://doi.org/10. 1007/s00395-012-0304-2.

Wang, N., De Vuyst, E., Ponsaerts, R., Boengler, K., Palacios-Prado, N., Wauman, J., ... Leybaert, L. (2013a). Selective inhibition of Cx43 hemichannels by Gap19 and its impact on myocardial ischemia/ reperfusion injury. Basic Research in Cardiology, 108(1), 309. https:// doi.org/10.1007/s00395-012-0309-x.

Wang, N., De Bock, M., Decrock, E., Bol, M., Gadicherla, A., Bultynck, G., \& Leybaert, L. (2013b). Connexin targeting peptides as inhibitors of voltage- and intracellular $\mathrm{Ca} 2+$-triggered $\mathrm{C} \times 43$ hemichannel opening. Neuropharmacology, 75, 506-516. https://doi.org/10.1016/j.neuropharm.2013.08.021.

Wei, H., Deng, F., Chen, Y., Qin, Y., Hao, Y., \& Guo, X. (2014). Ultrafine carbon black induces glutamate and ATP release by activating connexin and pannexin hemichannels in cultured astrocytes. Toxicology, 323, 32-41. https://doi.org/10.1016/j.tox.2014.06.005.

Willebrords, J., Maes, M., Crespo Yanguas, S., \& Vinken, M. (2017). Inhibitors of connexin and pannexin channels as potential therapeutics. Pharmacology \& Therapeutics, 180, 144-160. https://doi.org/10. 1016/j.pharmthera.2017.07.001.

Ye, Z. C., Wyeth, M. S., Baltan-Tekkok, S., \& Ransom, B. R. (2003). Functional hemichannels in astrocytes: A novel mechanism of glutamate release. The Journal of Neuroscience, 23(9), 3588-3596.

\section{SUPPORTING INFORMATION}

Additional Supporting Information may be found online in the supporting information tab for this article.

How to cite this article: Walrave L, Pierre A, Albertini G, et al. Inhibition of astroglial connexin43 hemichannels with TATGap19 exerts anticonvulsant effects in rodents. Glia. 2018;66:1788-1804. https://doi.org/10.1002/glia.23341 